\title{
Pathogenic Fungal Infection in the Lung
}

\author{
Zhi Li ${ }^{1,2}$, Gen Lu ${ }^{1 *}$ and Guangxun Meng ${ }^{2 *}$ \\ ${ }^{1}$ The Joint Center for Infection and Immunity, Guangzhou Women and Children's Medical Center, Guangzhou Institute of \\ Pediatrics, Guangzhou, China, ${ }^{2}$ The Joint Center for Infection and Immunity, Institute Pasteur of Shanghai, Chinese Academy \\ of Science, Shanghai, China
}

Respiratory fungal infection is a severe clinical problem, especially in patients with compromised immune functions. Aspergillus, Cryptococcus, Pneumocystis, and endemic fungi are major pulmonary fungal pathogens that are able to result in life-threatening invasive diseases. Growing data being reported have indicated that multiple cells and molecules orchestrate the host's response to a fungal infection in the lung. Upon fungal challenge, innate myeloid cells including macrophages, dendritic cells (DC), and recruited neutrophils establish the first line of defense through the phagocytosis and secretion of cytokines. Natural killer cells control the fungal expansion in the lung via the direct and indirect killing of invading organisms. Adaptive immune cells including

OPEN ACCESS

Edited by:

Daniel M. Altmann, Imperial College London,

United Kingdom

Reviewed by: Mirian Nacagami Sotto, University of São Paulo, Brazil Darius Armstrong-James, Imperial College London, United Kingdom

*Correspondence: Gen Lu lugen5663330@sina.com Guangxun Meng gxmeng@ips.ac.cn

Specialty section

This article was submitted to Microbial Immunology, a section of the journal

Frontiers in Immunology

Received: 15 October 2018 Accepted: 18 June 2019 Published: 03 July 2019

Citation:

Li Z, Lu G and Meng G (2019) Pathogenic Fungal Infection in the Lung. Front. Immunol. 10:1524. doi: 10.3389/fimmu.2019.01524
Th1 and Th17 cells confer anti-fungal activity by producing their signature cytokines, interferon- $\gamma$, and IL-17. In addition, lung epithelial cells (LEC) also participate in the resistance against fungal infection by internalization, inflammatory cytokine production, or antimicrobial peptide secretion. In the host cells mentioned above, various molecules with distinct functions modulate the immune defense signaling: Pattern recognition receptors (PRRs) such as dectin-1 expressed on the cell surface are involved in fungal recognition; adaptor proteins such as MyD88 and TRAF6 are required for transduction of signals to the nucleus for transcriptional regulation; inflammasomes also play crucial roles in the host's defense against a fungal infection in the lung. Furthermore, transcriptional factors modulate the transcriptions of a series of genes, especially those encoding cytokines and chemokines, which are predominant regulators in the infectious microenvironment, mediating the cellular and molecular immune responses against a fungal infection in the lung.

\section{Keywords: pulmonary fungal infection, pattern recognition receptor, inflammasome, cytokine, chemokine}

\section{INTRODUCTION}

With the increasing number of immunocompromised patients, diseases caused by fungal infections remain a great threat in public health. Opportunistic fungi, including Aspergillus with invasive aspergillosis (1-3), Cryptococcus with cryptococcosis (4-6), Pneumocystis with pneumonia (7), and endemic fungi $(8,9)$ are the main sources of fungal infections in the lungs of humans. Although these infections are rarely found in the target organs in healthy people, they may result in life-threatening invasive diseases in patients with an impaired immune system. These individuals include patients suffering immunodeficiency disorders such as HIV/AIDS and cancer patients who undergo chemotherapy, as well as those patients who receive immunosuppressive therapy such as 
in bone marrow/stem cell transplantation. Pathogenic fungal infections in the lung has resulted in the incidence and infectious death of invasive mycoses especially in patients with severe defects of host immune responses $(10,11)$. Some fungal pathogens initiate the infection through surface proteins from pathogen-host interaction, finally leading to mycosis with multiple tissue lesions especially in immunocompromised patients as mentioned above. For example, Cryptococcus mainly infects the lung and invades the brain via circulation, leading to lethal cryptococcal meningitis. Cryptococcosis, including life-threatening Cryptococcal meningoencephalitis (12), afflicts about 1 million AIDS patients and causes more than 600,000 deaths worldwide annually.

To minimize the damage of fungal infections, the human body has shaped a set of unique and sophisticated defense mechanisms, in which host innate immunity plays a crucial role. Aiming to eliminate the fungal dissemination, two typical innate immune cells, namely macrophage and dendritic cells (DC) as defensive troops constitute the first line in multiple organs. Furthermore, these innate cells can connect innate and adaptive immunity by serving as specific antigen-presenting cells (APCs), by which fungal antigens could be presented, to prime naïve $\mathrm{T}$ cells. Upon recognition of fungal pathogens, innate immune cells are activated by pathogen associated molecular patterns (PAMPs) via specific pattern recognition receptors (PRRs) on the surface, for further intracellular signaling transduction. The PRRs involved in fungal detection identified to date include Toll like receptors (TLRs), C-type lectin receptors (CLRs) as well as NOD like receptors (NLRs) $(13,14)$. Although breakthroughs have been made in the field of host response to mycobiota, novel cellular and molecular mechanisms on antifungal immunity remain to be established for the control of fungal infection and associated organ damage (Figure 1).

Despite antifungal drugs conferring protection against the pulmonary fungal infection $(15,16)$, drug resistance is still a severe problem. To reduce the incidence and death rate of pulmonary mycoses, efforts for the investigation on the mechanisms of pulmonary fungal infection, remain a requirement from both basic and clinical aspects. In the current review, we will discuss concrete research progress made on mycobiota regarding respiratory tract infections including Aspergillus, Cryptococcus, Pneumocystis, and endemic mycoses.

\section{PATHOGENS: THE CHARACTERIZATION OF FUNGAL INFECTIONS IN THE LUNG}

\section{Aspergillus and Cryptococcus Are the Major Fungal Pathogens in the Lung Infection}

Aspergillus mold is one of the most common fungal species which can sufficiently sporulate with released airborne conidia. The produced conidia in the air are small enough (2 to $3 \mu \mathrm{m})$ to arrive at human airways and pulmonary alveoli, causing a spectrum of diseases including lethal infections in immunocompromised individuals and in atopic patients with asthma allergies $(1,17)$. In healthy individuals, inhaled conidia are engulfed by alveolar macrophages and killed in a phagocyte oxidase-dependent fashion (18-20). In immunocompromised individuals, incomplete killing of inhaled fungal conidia results in germination and tissue invasion by fungal hyphae (21).

Cryptococcosis is caused by Cryptococcus exposure to the lung after the airborne organisms' inhalation. As a subtype of Cryptococcus, Cryptococcus neoformans distribute widely, particularly in soil and avian habitats. The most severe outcome of Cryptococcus infection is cryptococcal meningitis. Because $C$. neoformans and Cryptococcus gattii can disseminate from the lung to invade the brain by crossing the blood brain barrier (BBB), the fungal cells directly penetrate the $\mathrm{BBB}$ via endothelial cells on the blood vessels of the brain, using a "Trojan horse" strategy that is involved in the transport of phagocytes (5). In animal experiments, by counting yeast cell numbers in the brain, C. neoformans still remained in the CNS where large scale colonization and tissue injury could occur in spite of defense mechanisms employed by the host (22).

\section{Pneumocystis and Endemic Mycoses Cause Infections in the Lung}

Pneumocystis pneumonia (PCP) induced by fungal pathogen species Pneumocystis such as Pneumocystis jirovecii is the most common AIDS-defining disease, and is also found in non-HIV immunocompromised patients with deficiency in adaptive immunity, or individuals taking prolonged high-dose systemic glucocorticoids (11). The Pneumocystis antigens are primary surface glycoprotein (Msg or glycoprotein A) (23) and Pneumocystis protease, kexin (Kex1, Prt1). As a potential therapeutic target, Kex is supposed to participate in the proteolytic processing of Pneumocystis surface antigens $(24,25)$.

Endemic mycoses usually occur in restricted geographic areas, which can result in severe and fatal cases in hospitalizations $(26,27)$. In immunocompromised patients, endemic mycoses can also cause more severe and disseminated disease resulting in higher mortality (28). In many regions, increased incidence of endemic mycoses is correlated with a growing population of immunocompromised subjects (29). Surprisingly, mortality is also high in non-immunocompromised hosts (27). In North America, three major endemic mycoses including coccidioidomycosis, histoplasmosis, and blastomycosis could present as community acquired pneumonias (CAP) (27). For coccidioidomycosis in the southwest endemic areas, half of the infected people are asymptomatic, as an acute infection resembles respiratory symptoms such as pneumonia and bronchitis and a fever, which then experiences a selflimited process, and only very few cases can develop into disseminated infection; histoplasmosis, caused by infectious agent Histoplasma. capsulatum, are considered a community acquired infection with an exposure history to soil containing bat or bird droppings, patients also present pneumonia symptoms described as acute/chronic pulmonary histoplasmosis, severe cases may culminate in respiratory failure and death. However, blastomycosis is less common than histoplasmosis and coccidioidomycosis. As to the management of the endemic 


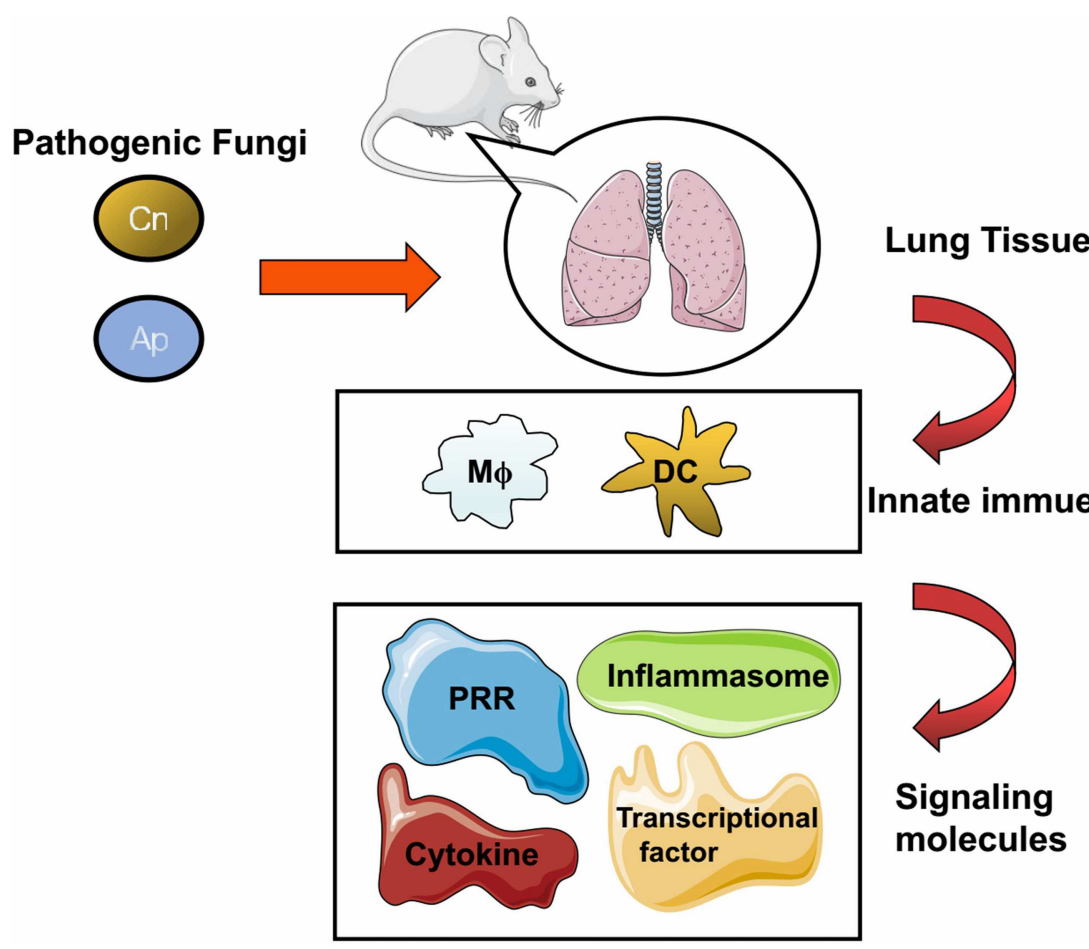

FIGURE 1 | General cellular and molecular components against fungal infection in the lung. The pathogenic fungi including Cryptococcus neoformans (Cn), Aspergillus (Ap), Pneumocystis (Pc), and Endemic fungi (Ef) can cause pulmonary infection in human and in murine models. Fungal pathogens could trigger host immune response upon inhalation, and lung tissue is the major infectious target of these pathogens. Once the infection is initiated, multiple cells either resident in the lung tissue or recruited from blood and lymphoid organs are motivated to clear the invasive fungi. After entering host cells, molecules including receptors, adaptors, or effectors come into play with divergent roles to respond to the fungal challenge.

mycoses-caused community acquired pneumonia, antifungal treatment is deemed important, and azole therapy such as oral fluconazole is preferred (30). In addition, paracoccidioidomycosis has its geographic distribution mainly in Latin America where Brazil largely accounts for the reported cases (31).

\section{The Characteristics of Human Responses to Fungal Infection: A Distinct Susceptibility Between Immunocompromised and Immunocompetent Hosts}

The clinical case of human cryptococcosis was first described by German scientists in a young woman with inflammatory symptoms on the tibia (32). The lungs and brain are the major target organs for the cryptococcus organism causing human cryptococcosis: pulmonary cryptococcosis is caused by the entry of pathogenic airborne spores (conidia) or dried yeast cells into the airway and lungs; Cryptococcal meningitis (CM) is the infection from occasional sits (preferentially from lung or elsewhere such as skin, liver etc.) disseminating during the early phase via circulation into other parts of the body especially to the central nervous system (CNS) (33-35). Cryptococci can utilize parasitized phagocytes (monocytes/macrophages) to cross the
$\mathrm{BBB}$ into the brain via a Trojan horse smuggling the pathogens in Charlier et al. (36) and Kim (37). The outcome of fungal colonization in the lungs include either clearance of fungi by the host immune system or by establishing an infection from the asymptomatic infection at the latency period, into a virtual local inflammation characterized by pulmonary nodules and pneumonia, or the development of a subsequent dissemination into the systemic organs, preferentially into the CNS through the BBB. Therefore, cryptococci could be detected mainly from lung tissue/bronchoalveolar lavage/sputum or cerebrospinal fluid or blood, and CM has been considered to be severe and life-threatening mycosis with a high mortality derived from cryptococcosis. According to the immune reaction to a diverse polysaccharide capsule, the encapsulated cryptococcus could be classified into four serotypes (from A to D) and two major species are responsible for opportunistic cryptococcosis: the $C$. neoformans (serotype A and D) and C. gattii (serotypes B and C), which are infectious in immunocompromised hosts and in immunocompetent or immunologically normal individuals, respectively $(32,38-40)$. In the AIDS epidemic, $\mathrm{CD}^{+} \mathrm{T}$ lymphocytes deficiency renders HIV/AIDS patients less resistant to cryptococci, thus the rise in cases of human cryptococcosis was followed by the increasing diagnosis and morbidity of HIV/AIDS despite the development of antiretroviral therapy $(6,41,42)$. The lung serves as a target organ in patients with HIV/AIDS, but once 
infected, the likelihood of meningitis is high, possibly because the dissemination of cryptococcosis into the brain depends on the status of the pulmonary immune responses (43). On the other hand, highly encapsulated cryptococci are more frequently found in the respiratory tracts rather than the CNS, which resist phagocytes and reduce the rate of systemic dissemination (44). In a basic study, severe combined immunodeficiency (SCID) mice inoculated intravenously (i.v.) with C. neoformans viable cells could mimic systemic cryptococcosis in immunodeficient hosts (45). Of note, cryptococcosis in HIV-negative patients is not rare as previously thought (46), these individuals show no apparent immune deficiency but under immunosuppressive conditions including: immunosuppressive drug treatment (glucocorticoids or other immunosuppressants) and malignancies or hematologic disorders (chronic leukemia, lymphoma), the presence of systemic lupus erythematosus patients receiving immunosuppressive agents, and other diseases e.g., diabetes mellitus, cirrhosis, and chronic renal failure, also contribute to cryptococcosis in HIV-negative patients. Interestingly, although the development of the immune system in children is insufficient, pulmonary cryptococcosis in children is rarely observed but can often be a fatal disease (47) (Figure 2A).

Invasive pulmonary aspergillosis (IPA), an opportunistic mycosis, results from a pathogenic Aspergillus infection in the lung. Susceptible individuals on Ap are very similar to those on C. neoformans, Aspergillus poses a serious threat to immunocompromised individuals including hosts with cancer or hematological disorders (acute leukemia, neutropenia), patients with chronic granulomatous diseases, and immunosuppressed bone marrow/organ transplant recipients (48-51). In contrast, inhaled infectious propagules in immunocompetent hosts show no further significance because of the strong resistance to the fungus, with killing and clearance by the cells of the pulmonary immune system (Figure 2B).

Regarding the process of human infection establishment, we elucidate that as an "unbalanced fight between host and pathogen," on one hand, the immunocompromised host or patient with underlying immunosuppressive conditions are characterized by the cellular immune deficiency: impairing the killing and clearance ability of phagocytes e.g., resident alveolar macrophages and weakened cellular immunity mediated by CD4 T lymphocytes, both of which contribute to host resistance to the fungi; in addition, the encapsulated cryptococcus resist the phagocytosis and rapidly germinate into mature yeast cells to establish an infection in the host. For the therapy of mycoses, Amphotericin B (AMB), fluconazole and echinocandins are the optimal antifungal agents (52-54), but occasionally current antifungal drugs may not cure these diseases due to a growing antifungal drug resistance, toxicity and side effects which still pose a potential risks for patients (55). Therefore, novel strategies rather focus on host defense, which is a crucial determinant of fungal pathogenesis. At present, the biggest problem in the treatment of invasive mycoses, is the ineffectiveness of antifungal agents, and new therapeutic immunomodulators are urgently required. Additionally, poor prognosis is attributed to the severe CM in the brain. Therefore, therapeutic strategies for both enhancing the clearance of pathogens and the prevention of dissemination into the CNS, are still required (Figure 2C).

\section{Pathogen-Host Communication: The Recognition and Internalization of the Fungi by the Host Innate Immune System in Initial Signaling}

To understand the communication between host and fungal pathogens would be useful for the diagnosis and therapy of the trajectory of infection. However, the signaling events for fungal pathogens and mammalian host cell interactions remain poorly understood, although some research progress has been made in this direction (56).

The fungal surface is mainly comprised of chitin, modified glycoproteins and glucans. In most yeasts, mannose-containing polysaccharides are often covalently attached to proteins. $C$. neoformans is a unique pathogenic fungus which employs a specific polysaccharide component (glucuronoxylomannan, GXM) as a capsule outside the cell wall, with anti-phagocytosis activity (57). GXM in the C. neoformans capsule is essential for virulence of this pathogen. In fact, patients with cryptococcosis accumulate GXM in the cerebrospinal fluid and serum, where it is associated with several immunomodulatory properties.

The fungal surface polysaccharides or glycans are the main PAMPs recognized by host cells, while the surface proteins on different fungi are essential for their virulence and intracellular survival. It is known that phagocytosis by host cells is an early event in the host-microbe interaction (58). The precise mechanisms that mammalian host cells coordinately manipulate fungal phagocytosis and replication with, remain complex and elusive. Professional phagocytes, for instance macrophages, can internalize and kill large particulate material through the phagocytosis process involving reactive oxygen species (ROS) (59). Binding of pathogenic particles to cell surface receptors, with a reorganization of the membrane and intracellular elements, would result in the phagocytosis of particle and phagosome formation. Notably, engulfment of the fungal pathogens triggers the host autophagy initiation complex (AIC) and the upstream kinases, which can mediate autophagy in the $C$. neoformans infection (60).

\section{HOST: CELL POPULATIONS IN HOST DEFENSE AGAINST PULMONARY FUNGAL INFECTIONS}

Although mounting signal mechanisms driving the initiation and development of fungal infection investigated by independent groups have been clearly revealed, we have a relatively poor view about the integrated cellular and molecular systems involved in the process of distinct fungal infection in the lung. Thus, effective therapeutic approaches that tackle harmful pulmonary fungal infection and inflammation, remains limited. Host mechanisms of fungal infection in the lung derive from multiple cell types and numerous molecules including receptors, adaptors, kinases, and transcriptional factors in the fungal pathogen challenge. Here we highlight the representative components in the host response, 


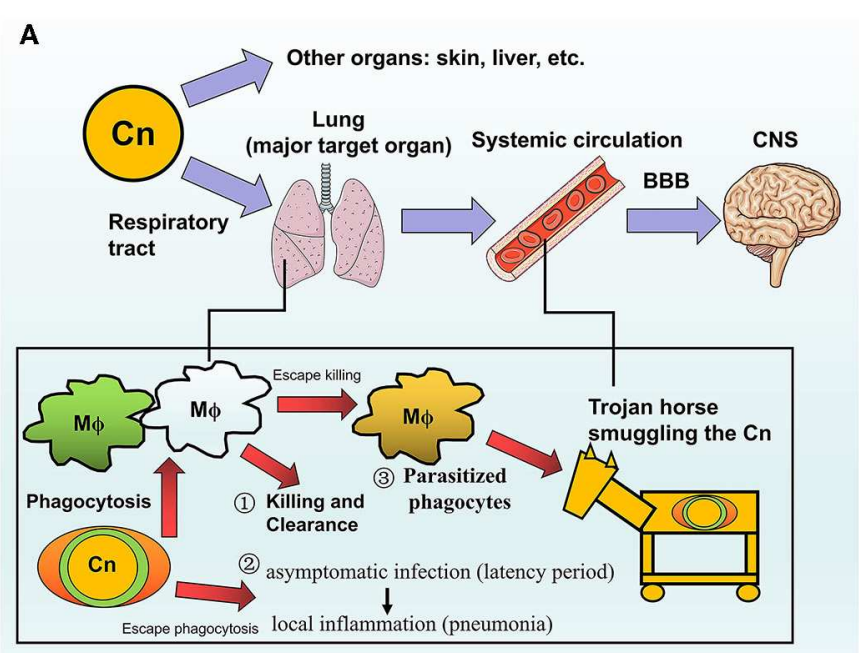

B

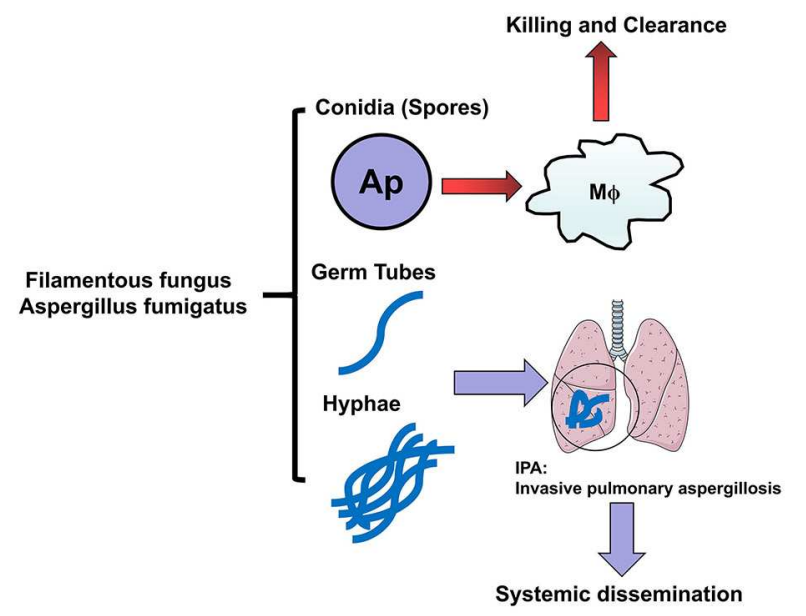

C

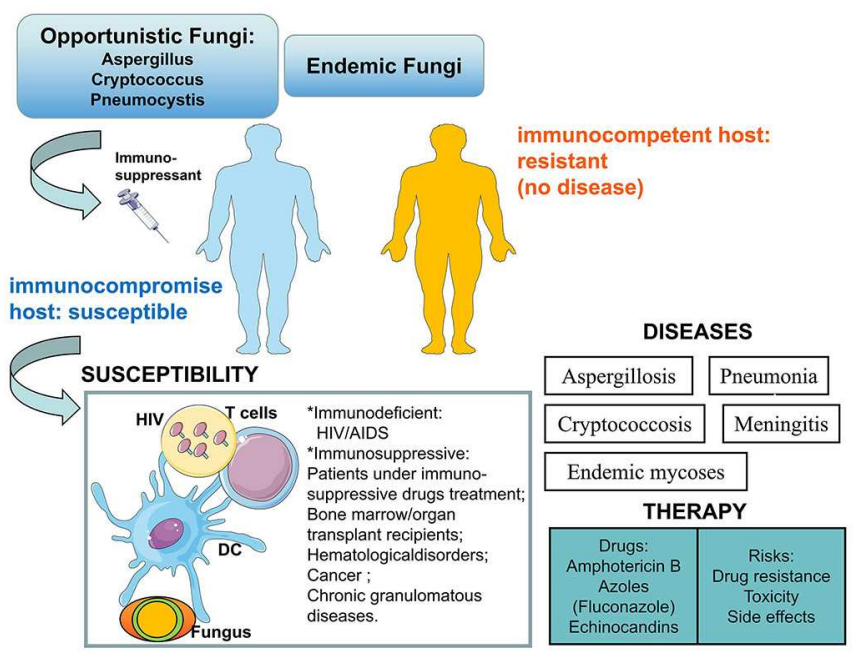

FIGURE 2 | The human fungal infections in the lung. (A) Cryptococcus neoformans infection in human: how the pathogens invade into the brains? Cryptococcus neoformans $(\mathrm{Cn})$ is more aggressive to the lung via respiratory the tract compared with other organs (skin, liver, etc.), where outcomes of fungi-host communication 
FIGURE 2 | are: (1) Killing and clearance by macrophages after phagocytosis, (2) The encapsulated fungi are able to escape from phagocytosis and further establish virtual infection after pulmonary colonization, from asymptomatic latency period to local inflammation such as pneumonia, (3) Part of the phagocytosed fungi could escape from killing and further parasitize the host cells like a Trojan horse which transports the pathogenic fungi into the CNS via circulation. After crossing the BBB, $\mathrm{Cn}$ that accumulates in the CNS would result in lethal cryptococcal meningitis especially in susceptible hosts. (B) Aspergillus fumigatus in humans: Hyphae are the pathogenicity for IPA. Aspergillus fumigatus are a Filamentous fungus in the lung. Inhaled conidia (spores) could be ingested and killed by the alveolar macrophage constructed first line of host defense, while the escaped conidia grow into mature germ tubes and hyphae, which not only cause Invasive pulmonary aspergillosis (IPA) but also lead to systemic dissemination by invading vessels. This pathological process is more common in patients who lack an effective host defense or hyphal defense. (C) Summary of fungal infection to human hosts. Opportunistic fungi or endemic fungi infection usually occurs in hosts with a profound immune deficiency involving HIV/AIDS, or immunosuppressed patients involving hematopoietic stem cells (HSCs) or solid organ transplantation, immunosuppressant, or

glucocorticosteroid therapy, hematological disorders (leukemia, lymphoma), cancer, and chronic granulomatous diseases. In susceptible hosts, multiple factors participated in this process including HIV, Fungus, immune cells, or even the immunosuppressant and transplanted organs. Infection and subsequent inflammation result in diseases e.g., Mycoses, pneumonia, and meningitis. The current anti-fungal treatments include azoles and Amphotericin B, but potential risks also lead to the ineffectiveness of the drugs.

from cell biology and molecule biology focusing on Aspergillus, Cryptococcus, and other pulmonary fungi.

Innate immunity plays a central role in host protection against fungal infection. Invasive pulmonary aspergillosis (IPA), candidiasis, and other mycosis can develop in the hosts with specific immune deficiency defects, such as chemotherapyinduced prolonged neutropenia or functional defects in NADPH oxidase. After the initial sensing of fungi by pattern recognition receptors (PRRs), neutrophils, and macrophages are recruited as first line immune cells to the infected and inflammatory sites for their clearance of fungal pathogens at an early stage of infection. Fungal antigens can be presented by DCs which also bridge innate and adaptive immunity. In fact, the innate immune system orchestrates the first step to protect hosts against fungal infection in the lungs (Figures 3A,B).

\section{Phagocytic and Myeloid Derived Innate Cells: Alveolar Macrophages and Neutrophils, and Dendritic Cells}

Multiple innate immune cells as well as adaptive $\mathrm{CD} 4^{+}$Th1 type cells constitute a precise network for the host defense against pulmonary fungal pathogens $(61,62)$, In particular, lung phagocytic leukocytes including the resident alveolar macrophages (AM), DC and neutrophils often functionally modulate the early immune response to pulmonary infection in the first line with an armored defense against pulmonary fungal infections (63). A study reported that $\mathrm{CD}_{11 \mathrm{c}^{+}} \mathrm{AM}$ population is dominant in uninfected lungs as well as in the early days following infection with $C$. neoformans. Thereafter, the rapid expansion of $\mathrm{CD} 11 \mathrm{c}^{+}$cells is attributed to accumulated pulmonary DCs. Here CD11b expression is used to distinguish between $\mathrm{AM}\left(\mathrm{CD} 11 \mathrm{c}^{+} \mathrm{CD} 11 \mathrm{~b}^{\mathrm{min}}\right)$ and conventional DC $\left(\mathrm{CD} 11 \mathrm{c}^{+} \mathrm{CD} 11 \mathrm{~b}^{+}\right)$. It was indicated that $C$. neoformans infected mice with AM/DC population depletion, displayed very rapid deterioration (63). Alveolar macrophages mount inflammatory responses to fungal pathogens with specific productions of tumor necrosis factor- $\alpha$, interleukin$1 \alpha / \beta$, interleukin-6, macrophage inflammatory proteins, and granulocyte-colony stimulating factor, which mainly depends on signaling from recognized fungal glucan via host PRR dectin-1 (64).
Neutrophil is a key orchestrator during the infectious process, particularly for polymorphonuclear neutrophils (PMN). These cells can initiate quick lung infiltration and arrive at inflammatory sites rapidly where it plays a vital role in eliminating pathogens and promoting tissue repair. At the early phase of Aspergillus fumigatus infection, AM and neutrophil coordinately shape the host defense and survival following fungal inhalation, AM is believed to kill conidia while neutrophil is postulated to restrict the tissue invasion of hyphae (61). A well-established method of transient neutrophil depletion by antibody RB6-8C5 (anti-Ly6G/Ly6C) can be used to evaluate the temporal demand for neutrophils in the host defense (65). RB6-8C5 induced neutropenia both in circulation and in single cell lung suspensions without affecting the CD11b+Ly6C+Ly6G- monocytes, leading to invasive aspergillosis and tissue damage (66). Mice who received RB6-8C5 prior to or within $3 \mathrm{~h}$ after infection were exacerbated as shown by higher susceptibility and death rates, and this is different from the depletion at later time points when the survival rates are nearly normal. Neutrophil is also a type of IL-17, producing cells in several mouse infectious models. Eric Pearlman demonstrated that in A. fumigatus infection Ly6G+Ly6C+ neutrophil is activated through IL-17A-IL-17RC interactions via multiple molecules including dectin-2 and IL17 signaling related IL-6, IL-23, RORgt (67). In addition, neutrophil activity could be governed by TLRs in Aspergillosis (10). Recognition of A. fumigatus conidia trigger non-oxidative intracellular killing involving integrin CD11b/CD18 and PI3K. When the conidia germinate, by escaping from early killing, the extracellular destruction of the Aspergillus hyphae requires antibody mediated opsonization with the involvement of Fc $\gamma$ receptors recognition and kinase signaling for downstream ROS related metabolites production via MPO and NADPH oxidase (68).

Phagocytic leukocytes in the lung such as AM, DC, and recruited neutrophils constitute the first immune defense by phagocytosing pathogens with yeast lysis upon Aspergillus or Cryptococcus exposure after inhalation. Therefore, the resident AM and DC contribute to the early innate immune response and later adaptive immunity regulation. Dendritic cells (DCs) are the classic innate immune cell type which potentially trigger and control adaptive immunity mainly mediated by $\mathrm{T}$ and $\mathrm{B}$ lymphocytes $(69,70)$. Pulmonary 


\section{A}
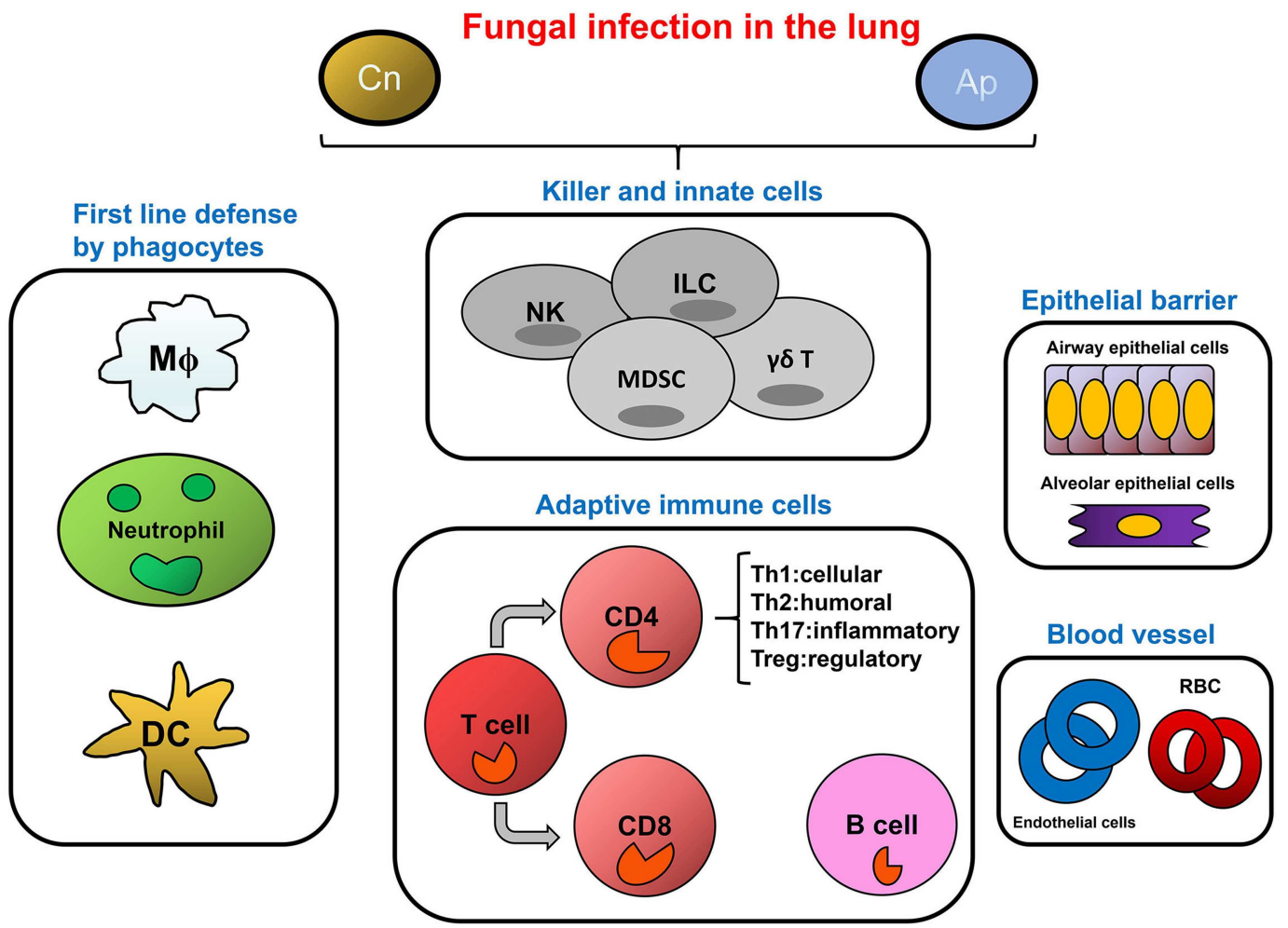

B

\section{Concerted cellular defense against pulmonary fungal infection}

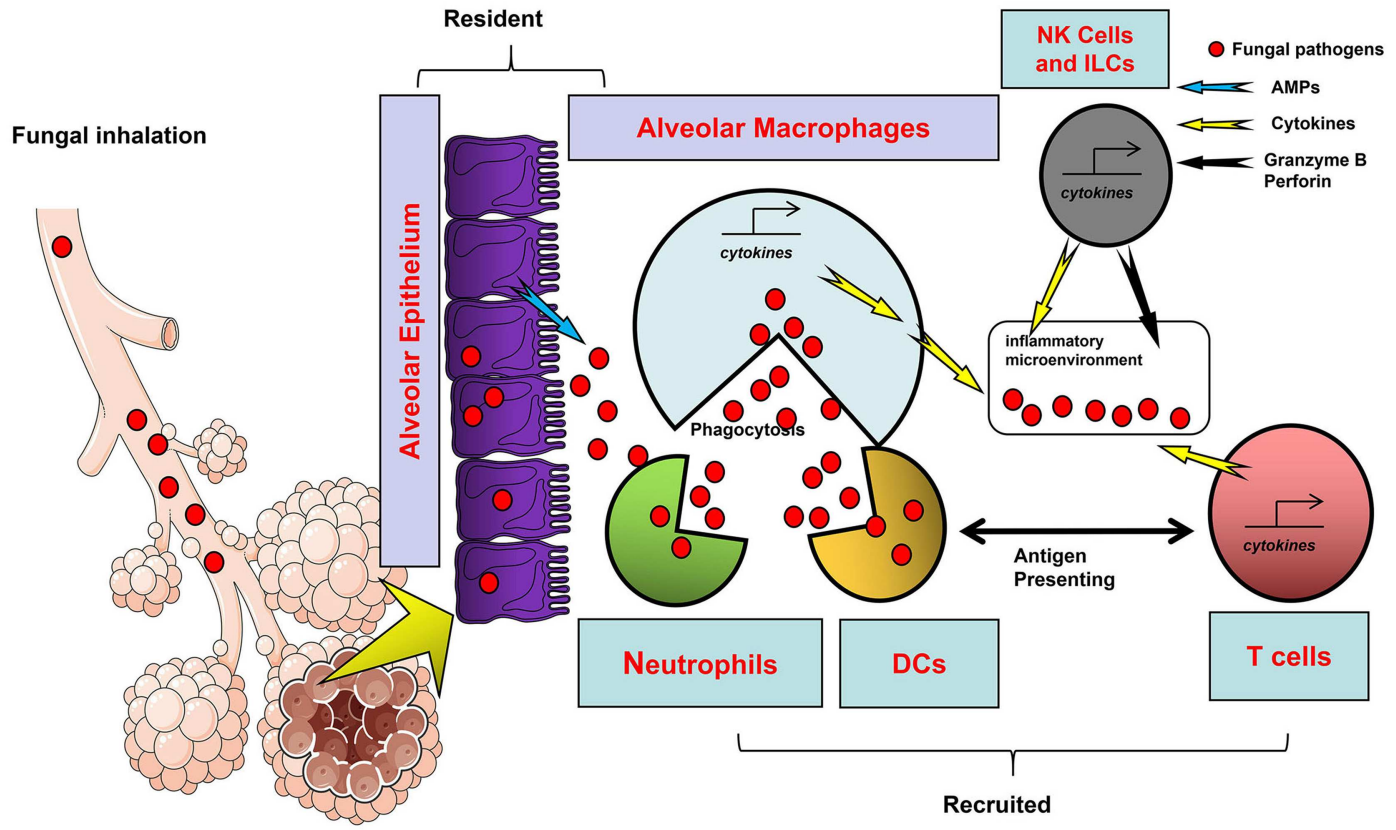

FIGURE 3 | The Network of cellular defense against fungal infections in the lung. (A) The cell category in host response to infection. (B) Divergent cell types orchestrate the host defense against fungal infection. To defend against pulmonary fungal infection as represented by $\mathrm{Cn}$ and Ap, divergent types of cells are involved 
FIGURE 3 | in the microenvironment of infectious sites in the lung. Among them, granulocytes and monocytes/macrophages as well as DCs are typical myeloid lineages which are the major cellular agents for innate immunity. In the respiratory tract, these cells constitute the first line of defense. Alveolar macrophages are monocytes/macrophages specifically resident in the lung; neutrophils are quickly infiltrated to the sites of inflammation to eradicate the pathogen and to promote tissue repair; pathogens, or antigens bind to DC-SIGN expressing immature DC to gain access to these cells for uptake, meanwhile activating DCs trigger adaptive immunity mediated by the T cells. The direct anti-pathogen effect of NK cells, as a central player of innate immunity, is ascribed to their direct cytotoxicity and cytotoxic cytokine and granule-secreting capacity. In addition, other innate like cells such as ILC and special T cell types such as $\gamma \delta T$ cells also contribute to the host defense by cytokine secretion or other approaches, with concomitant inducement of MDSC. For adaptive immunity, CD4+ Thelper cell immunity is predominant in the pathogen-induced inflammation, IFN- $\gamma$ produced by active Th1 cells is beneficial for Cryptococcus clearance, and the Th17 cells with IL-17/IL-23 secretion also plays important roles in a pulmonary fungal infection. In contrast, Th2 cells with anti-inflammatory cytokine secretion and Treg cells with immunosuppression activity participate in the host response upon fungal infection usually with negative outcomes. In the microenvironment, secreted cytokines further regulate innate and adaptive cells function through cytokine receptors. Besides multiple immune cells, the epithelial cells at the mucosal barrier also confer a protective activity against the invasive fungi in the respiratory tract. In the lung blood vessel, the roles of endothelial cells and RBC have rarely been reported.

DCs also coordinate adaptive immune responses to $A$. fumigatus, by regulating $\mathrm{T}$ cell proliferation and enhancing the protective Th1 response within the lung (71-73). Dectin-1 is responsible for immature DCs pro-inflammatory responses after exposure to A. fumigatus (74). Interestingly, the neutrophils could mediate lung DC maturation and efflux (75), while DCs trigger the secreted chemokines for neutrophils/Th1 lymphocytes recruitment (76), suggesting the cellular interplays among neutrophils, DCs as well as T lymphocytes.

\section{NK Cells and T Lymphocytes}

Natural killer (NK) cells in the innate immune system confer primary immune protection against tumor and pathogenic microbes through granule-mediated killing and effector IFN- $\gamma$ release $(77,78)$. It was found that the adoptive transfer of $\mathrm{CD} 4^{+}$ $\mathrm{T}$ cells are responsible for the increase of NK cells with the activation marker NKG2D and the release of gamma interferon, granzyme B and perforin during Pneumocystis infection (79). Moreover, A. fumigatus can be recognized by human NK cells with direct response to hyphae but not conidia (80). Unlike other innate immune cells, NK cells do not directly defend the fungus through the phagocytosis process but appear to regulate their antifungal function via the production of inflammatory IFN- $\gamma$ (81). Similarly, murine NK cells are antifungal to $C$. neoformans by directly killing the organism (82). The precise mechanisms of natural killer cells' mediated defense against respiratory fungal pathogens and their interplay with other immune cells during infection are still limited and require further study.

The homeostasis of multiple adaptive T cell subtypes (typically the CD4 positive subtype including Th1/Th2/Th17/Treg cells) are involved in the further defense against the fungal pathogen after innate immunity. Although the crucial role of the initial innate immunity against pulmonary fungal infection in hostpathogen interplay have been well-described, the functions of adaptive immunity with representative $\mathrm{T}$ cell responses are equally of importance for the host's defense. A Th1 type adaptive immune response with Th1 cytokines such as IFN- $\gamma$ is often required for the clearance of $C$. neoformans yeast. For instance, previous studies have revealed that in mice infected with an IFN-gamma-producing C. neoformans strain, H99-gamma were resistant to a second infection in the lung by a lethal strain. In the respiratory tract, increased granulomatous formation, rapid inflammatory infiltration, and Th1 mediated adaptive immunity were involved in protection against cryptococcosis (83). Whereas, the mRNA expression profiles of pulmonary cytokines in infected mice were of Th2-type, IL-12 treatment protected mice from a lethal infection by regulating the host immune balance toward the Th1-state (84). Tregs and Th17 cells with IL-17 production exhibit opposite responses to aspergillosis, excessive inflammation driven by IL-17 augmentation and deduced Tregs with anti-inflammatory activity which led to a higher susceptibility to A. fumigatus in mice (85). In addition, $\mathrm{CD}^{+} \mathrm{T}$ cell regulation in fungal infection and the molecular mechanisms underlying fungal clearance, remain rarely reported. One study displayed that the protective and antifungal memory of $\mathrm{CD}^{+} \mathrm{T}$ cell responses are promoted by TLR3, which could serve as a new therapeutic target for aspergillosis in high-risk patients (86).

\section{Lung Epithelial Cells}

Multiple hematopoietic cells such as macrophages and DCs play crucial roles in anti-fungal immune resistance and tolerance to fungi, by keeping a balance of immunopathology/protective immunity. However, growing evidence implies that the epithelial cells play an essential role in infection and inflammation by releasing surfactant proteins and antimicrobial peptides (87). First, internalization of A. fumigatus conidia could also be performed by epithelial and endothelial cells (88). Lung epithelial cells (LEC) often play crucial roles in the crosstalk between fungal infection and mucosal immunity at pulmonary mucosa by linking the innate immunity and adaptive immunity. It is reported that the protective tolerance on LECs to $A$. fumigatus is achieved through indoleamine 2,3-dioxygenase (IDO) signaling (89).

\section{KEY MOLECULES REGULATING HOST IMMUNE RESPONSES TO FUNGAL INFECTIONS IN THE LUNG}

Various molecules play distinct but crucial roles in innate immunity, the present review also sheds light on molecular regulation, during immune tolerance, to pulmonary fungus (Figure 4A). 


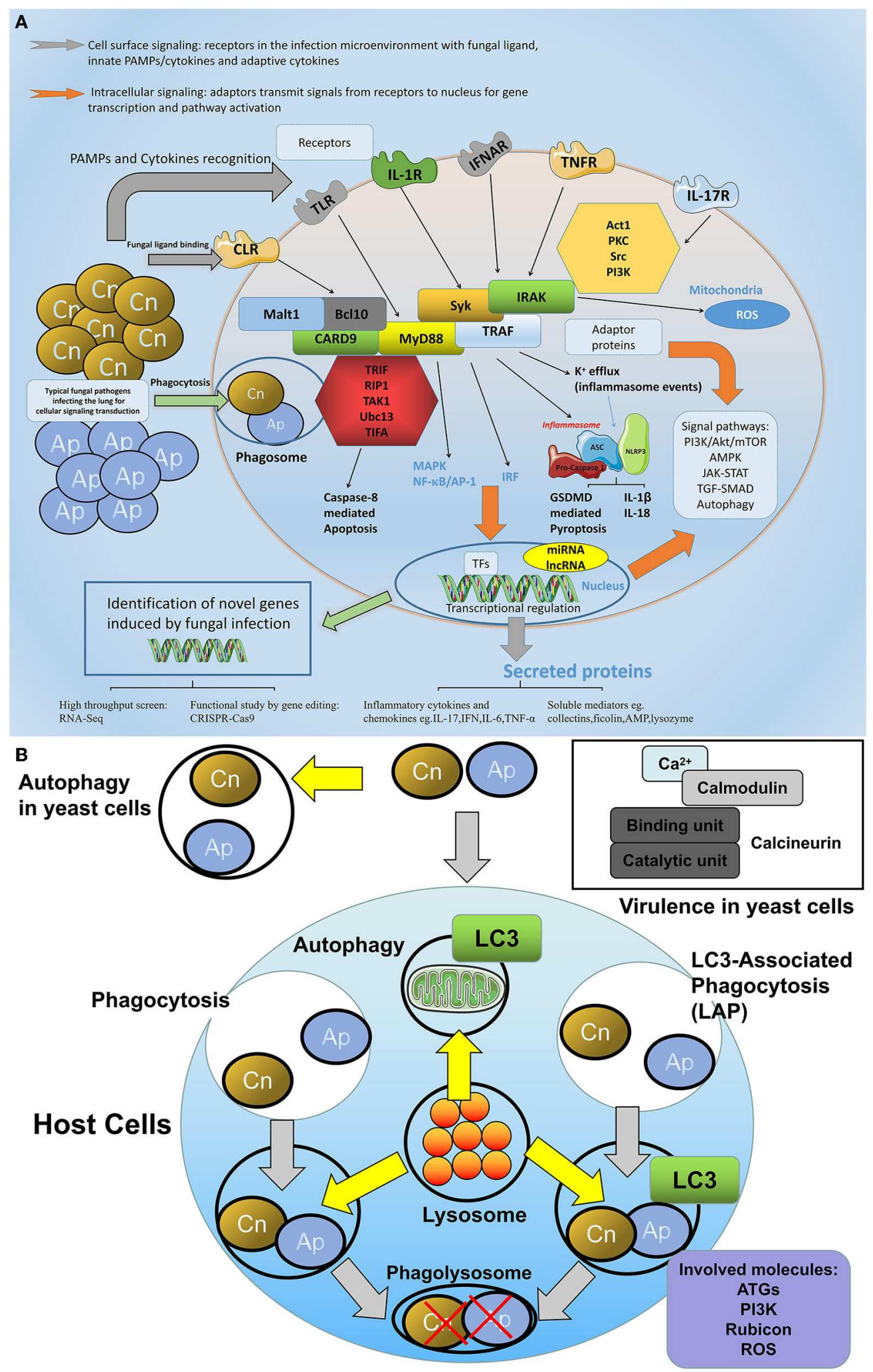

FIGURE 4 | The network of molecular defense against fungal infections in the lung. (A) General involved molecules and signal events in the aspects of cellular fungal infection. During fungal infection, various intracellular and extracellular molecules are involved in the host defense process. On the cell surface, receptors especially the 
FIGURE 4 | PRRs are predominant regulators that sense fungal pathogens or fungal associated PAMPs, among them C-type lectin receptors (CLRs) including dectin-1, dectin-2, and MR play crucial roles in fungi-host communication. Toll-like receptors are also engaged in fungal recognition. In addition, cytokine receptors such as IL-1R, TNFR, or IFNAR are also activated upon receiving the respective cytokine signals. For intracellular signaling, adaptor proteins such as MyD88, CARD9, Syk, and TRAF are able to transmit signals via divergent pathways, leading to MAPK/NF- $\mathrm{kB}$ activation or type I interferon production, or inflammasome assembly. These pathways either trigger protein modulation such as translocation, phosphorylation, and ubiquitination, or at a transcriptional level, regulates gene expression in the nucleus, which leads to cell activities such as proliferation, apoptosis, or pyroptosis. (B) The autophagy and calcineurin signaling in the host-fungi during infection. The autophagy and calcineurin signaling are important for the host-fungi bioactivity regulation. Autophagy could occur in both yeast cells and host cells. LAP is a special intracellular autophagy which forms to defend extracellular fungi internalized and which combine the characters of both phagocytosis and autophagy: pathogens are entrapped in the phagosome with LC3 recruitment, and the lysosome is involved in the fusion of the phagolysosome where engulfed pathogens are killed by degradation. Key molecules including ATG, PI3K, Rubicon, and ROS play roles in the fungi induced LAP signaling. In yeast cells, calcineurin transmitting calcium and calmodulin signaling is responsible for the virulence of the pathogen.

\section{Receptors}

\section{PRRs Including CLRs and TLRs}

Signaling transductions, through host receptors in an infection, are relatively well-studied. In addition to fungi-derived PAMPs $(13,14)$, some host-encoded molecules, and the damageassociated molecular patterns (DAMPs), are secreted during fungal infection for host defense (90). CLRs and TLRs/IL$1 \mathrm{R}$ are classical and predominant PRRs engaged for fungal pathogen recognition. CLRs are a group of important C-type lectin receptors including Dectin-1/2, MCL (Macrophage C-type lectin, Clec4d), Mincle (macrophage inducible C-type lectin, Clec4e), and MR (mannose receptor) that are all involved in fungal recognition (91-94). In a lung infection with $A$. fumigatus, dectin-1 expressed on resident alveolar macrophages and polymorphonuclear neutrophils is required for the initiation of a host response while the role of dectin-2 is not wellinvestigated (95). Recently, a C-type lectin receptor, and melaninsensing C-type lectin receptor (MelLec) was identified by the Gordon D. Brown group (96), which was fungicidal by sensing the unit of DHN-melanin in conidia of $A$. fumigatus. In animal models, MelLec was protective in the host against $A$. fumigatus. In humans, a single nucleotide polymorphism of MelLec was found to negatively regulate inflammatory responses by myeloid cells and increased the incidence of $A$. fumigatus infection in stem cell transplant recipients.

C. neoformans glycoantigens such as mannoproteins can bind different lectin receptors such as the mannose receptor and DC-specific non-ICAM3 grabbing nonintergrin (DCSIGN) (97, 98). Phagocytosis of pathogens by myeloid cells upon PRRs recognition or exposure to soluble glycoantigens and cryptococcal DNA, would lead to cytokines/chemokines production as well as yeast lysis. Moreover, various TLRs are distributed on different immune cells, for resident alveolar macrophages, the TLR2, TLR4, and TLR7 are highly expressed and immunosuppressed mice with TLR2 or TLR4 deficiency are more susceptible to invasive aspergillosis (99-102).

\section{Cytokine Receptors Such as IL-1R and TNFR}

IL-1R shares a high homology with TLRs in signal transduction (103) and TLR/IL-1R signaling is critically involved in the response to fungal infections (104). The complex group of TNF ligands and the receptor superfamily serve as a rich source of drug targets on both innate and adaptive immunity. As a member of the tumor necrosis factor receptor superfamily, the $\mathrm{T}$ cell expressed glucocorticoid-induced TNFR-related protein
(GITR, TNFRSF18), mediates both natural and acquired immune reactions by its ligand GITRL expressed on APC. Intriguingly, GITR-GITRL could influence TLR2 and TLR4 expression on $\mathrm{DC}$ and correlated with $\mathrm{T}$ cells response during candidiasis (105). However, the effect of GITRL-GITR on DC and its relationship with Treg during aspergillusis and cryptococcosis remains unclear (106).

\section{Adaptor Molecules}

The TLR-mediated signaling pathways for downstream NF-кB activation events are important for the host immune regulation against fungal infections. Signaling by the TLR or IL-1R could employ multiple adaptor proteins including MyD88, TRAF6, TRIF, etc. for downstream signal cascades transduction.

\section{MyD88}

Previous studies on the innate immune mechanisms revealed a remarkable conservation of molecular components of host defense signaling pathways, among them the Toll-IL-1R homology (TIR) domain, presented by adaptor protein MyD88, is essential for signal transduction. The downstream NF-кB activation could be induced by adaptor MyD88 via the human TLR/IL-1R transduction pathway, through IRAK and TRAF6 (107). Under the condition of fungal infection, overexpression of MyD88 was functionally enough for the induction of fungicidal peptide Drosomycin in vitro. A recent study found that MyD88 also plays an important role in host defense during a respiratory fungal attack especially at the first phase of infection. Ubiquitous airborne conidia could be formed by A. fumigatus and inhaled by humans daily, in this process, adaptors including MyD88 and CARD9 could be activated via host receptors such as the C-type lectin receptor, TLR, and IL-1R for immune signaling transduction as well as fungal clearance. At the onset of respiratory fungal infection, MyD88 depletion delayed neutrophil lung trafficking and chemokines production, leading to injury in the lung. MyD88 expressed on lung epithelial cells, was responsible for rapid neutrophil recruitment and chemokines production through IL-1R. Exogenous CXCL1 treatment also rescued mortality in MyD88-deficient mice. Altogether, host MyD88 associated pathways play essential roles in early responses to A. fumigatus in the lung, and fungal PAMPs to host PRRs triggered MyD88-NF- $\kappa$ B signaling, serves as a pivotal pathway for the pathogen-host interaction $(100,108)$. 


\section{TRAF Family Proteins}

Besides MyD88, TRAF family proteins especially TRAF3 and TRAF6 play a crucial role in regulating innate and adaptive immune responses. In TLR signaling, TRAF6 is dependent on MyD88 instead of TRIF, and TRAF6 differently modulates MyD88- and IRAK-1-induced activation of NF-кB $(109,110)$. Although TRAF6 and TAK1 are implicated in candida infection (111), the roles of these molecules in CLRs initiated signaling have not been studied. In canonical CLR signaling, both TRAF6-TAK1 interaction and spleen tyrosine kinase (Syk) phosphorylation are initial events involved for CARD9-Bcl10MALT1 complex and downstream MAPK and NF- $\mathrm{B}$ activation, adaptor Syk-coupled CLRs including Dectin1/2 and Mincle mediate innate immunity against fungal infection (92, 93, 112). Another study proved that Dectin-1-Syk and autophagy contributed to maturation of the A. fumigatus phagosome (113).

\section{The Inflammasome Complex Inflammasomes}

The inflammasomes comprised of several intracellular proteins are functionally essential for the regulation of innate immune responses. These complexes could be activated through PAMPs-PRRs or host derived DAMPs signaling and are intensely associated with various infectious pathogens including fungi, viruses, and bacteria especially in a respiratory tract infection $(114,115)$.

\section{NLRP3 and AIM2}

NLRP3 and AIM2 are typical inflammasomes which play critical roles, with distinct mechanisms, in innate immunity: The NLRP3 inflammasome activation is regulated by two major steps of signals. First is the priming step in which NLRP3 and pro-IL$1 \beta$ expressions are induced in a NF- $\kappa \mathrm{B}$ dependent manner by PAMPs e.g., TLR agonists (LPS as representative one) or key cytokines e.g., TNF- $\alpha$ and IL-1 $\beta$. The second step is NLRP3 assembly activation by multiple stimuli e.g., ATP/nigericin. Further studies showed that phagocytosis of particulate matter triggers $\mathrm{K}^{+}$Efflux and activates NLRP3 $(116,117)$, but recently a $\mathrm{K}^{+}$independent activation mode was described via targeting mitochondria using small molecules (118). As to the biological function of the NLRP3 inflammasome in the field of infection, it plays a crucial protective role against several pulmonary fungi which could cause aspergillosis and cryptococcosis (90). Notably, NLRP3 inflammasome mediated signaling in the host immune defense is recognized by fungal polysaccharides such as curdlan $(119,120)$, and specifically A. fumigatus triggers the activation of the NLRP3 inflammasome via syk kinase activity and reactive oxygen species (121). In addition, fungal zymosan and mannan stimulated the NLRP3 inflammasome to induce macrophage and DC caspase- 1 activity as well as IL- $1 \beta$ secretion, suggesting that conserved cell wall components are responsible for the ASC and NLRP3 inflammasome activation during fungal infection (122). In cellular and animal models, acapsular mutant strain of C. neoformans (Cap59) but not the encapsulated wild type strain (H99), activates the inflammasome (123). Moreover, the germline NLRP3 knock-out mice infected with biofilm of clinical C. neoformans strain HS1101 displayed a more severe infection and inflammation in the lung, which is also true for Casp1 $\mathrm{KO}$ and ASC KO mice. These data illustrate the importance of the NLRP3 inflammasome components in the host responses to the fungal challenge in the lung (124). Absence in melanoma 2 (AIM2) is a unique DNA-sensing receptor. Mice lacking AIM2 alone displayed similar susceptibility compared with wild type mice upon Aspergillus infection, meanwhile mice with double knockout of AIM2 and NLRP3 failed to control Aspergillus hyphae dissemination, thus they succumbed to the attack of fungus more rapidly than wild type mice or mice deficient in either AIM2 or NLRP3 (125). Until now, the functions and mechanisms of other novel host inflammasomes such as NLRP1, NLRC6, NLRP7 in controlling fungal infection, remain elusive.

\section{NF- $\mathrm{KB}$ and MAPK}

$\mathrm{NF}-\kappa \mathrm{B}$ plays a critical role in the control of infection as well as inflammation, it was shown that the macrophage dectin1, TLR2 and TLR4 could specifically recognize the mature hyphal forms of Aspergillus but not spores, resulting in NF-кB dependent inflammatory cytokine secretion and antimicrobial ROS production (126). As to dectin-2, it was also reported that $\mathrm{I} \kappa \mathrm{B} \alpha$ (inhibitor of the kappa $\mathrm{B}$ protein) phosphorylation and NF- $\kappa \mathrm{B}$ activation following $A$. fumigatus stimulation occurs through dectin-2-Syk signaling (127). Interestingly, gliotoxin as a toxic metabolite synthesized by $A$. fumigatus specifically inhibits NF- $\kappa$ B activation and induces apoptosis (128). However, another paper found that ERK but not p38 was essential in the MAPK pathway responsible for defense against A. fumigatus on Alveolar Macrophages, whereas NF- $\kappa$ B activation appeared to play a secondary role. After phosphorylation by upstream molecules, the MAPKs translocated to the nucleus to phosphorylate downstream target molecules which transcriptionally regulated cytokine genes (129). Different from macrophage detecting Aspergillus via TLR2/4 to trigger TLR-MyD88-NF- $\kappa \mathrm{B}$-dependent synthesis of inflammation related molecules, pulmonary epithelial cells could sense sprouting but not resting spores of $A$. fumigatus to induce the synthesis of interleukin (IL)-8 through p38 MAPK and ERK1/2 and PI3 kinase, suggesting that MAPK is of importance both on phagocytes and epithelial cells (130). In addition, TLR4 in conjunction with CD14 could be involved in the host defense against $C$. neoformans capsular polysaccharide glucuronoxylomannan (GXM), stimulating NF- $\mathrm{B}$ nuclear translocation in macrophages without MAPK activation and TNF- $\alpha$ release (131).

\section{Cytokines and Chemokines}

Cytokines/chemokines are predominant modulators secreted from the host in response to various fungal pathogen infections. An imbalance between pro- and anti-inflammatory cytokines might negatively result in infectious diseases due to an impaired host defense.

\section{IL-1 Family Cytokines: IL-1 $\beta / I L-18 / I L-33 / I L-36$}

Until now, 11 members were identified in the IL-1 family of cytokines with seven proinflammatory cytokines including IL$1 \alpha$, IL-1 $\beta$, IL-18, IL-33, IL-36 $\alpha$, IL-36 $\beta$, and IL-36 $\gamma$ and four with anti-inflammatory cytokines including IL-1Ra, IL-36Ra, 
IL-37, and IL-38 (132). IL- $1 \alpha$ and IL-1 $\beta$ are thought to be the primary drivers of inflammation in chronic granulomatous disease via decreased autophagy and increased inflammasome activation (133). With respect to immunopathogenic effects of IL-1 family members during invasive pulmonary aspergillusis (IPA), both lung homogenates and alveolar macrophages derived from Dectin-1 KO mice demonstrated reduced IL-1 $\alpha / \mathrm{IL}-1 \beta$ and TNF, MIP, and KC in vitro (134), suggesting that IL- $1 \alpha$ and IL-1 $\beta$ production is derived from Dectin-1 signaling. A recent study has indicated that IL-1R was critical for protection, as IL- $1 \alpha$ was required for lymphocytes recruitment and IL- $1 \beta$ conferred resistance to fungal dissemination (135). Members of the IL-1 family often play protective roles in immune defense against the opportunistic mold $A$. fumigatus. Besides IL-1 $\beta$, IL18 is also protective against $C$. neoformans by inducing IFN- $\gamma$. IL-1 $\beta /$ IL-18 is primarily secreted in a NLRP3 inflammasomedependent manner as mentioned above. In a recent study, the IL-1 family member IL-33 played regulatory roles in lung infection defense against $A$. fumigatus. IL-33 expression was detected in the lung and increased after exposure to the fungus, independent of Dectin-1. Mice lacking the receptor for IL-33 (Illrl1 ${ }^{-/-}$) unexpectedly demonstrated enhanced lung clearance of the fungal pathogen while IL-33 administration to normal mice inhibited fungal-induced IL-17A and IL-22 through PGE2. Because normal mice produced less PGE2 after fungal exposure when administered IL-33, and PGE2 was significantly increased in fungal-exposed Il1rl1 ${ }^{-/}$mice, suggesting that IL33-mediated regulation of IL-17A and IL-22 occurred at the level of PGE2 This was confirmed by cyclooxygenase 2 or PGE2 inhibition, which attenuated fungal-induced protective IL-17A and IL-22, as well as IL- $1 \alpha$, IL-1 $\beta$, and IL- 6 productions in Il1rl1 ${ }^{-/-}$mice, resulting in impaired fungal clearance (132).

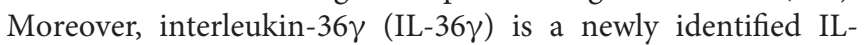
1 family inflammatory cytokine which is highly expressed on epithelium and some myeloid cells. Studies in humans have shown that A. fumigatus strongly induces IL-36g and IL-36Ra, but not IL-36 $\alpha$, which were dependent on dectin- 1 and TLR4 while Inhibiting IL-36 signaling was found to abrogate the induction of protective Th17 and Th1 responses (136).

\section{IL-17 and IL-23}

IL-17 (IL-17A) is a pleiotropic cytokine which has been implicated in the pathogenic development of autoimmune inflammations such as rheumatoid arthritis (RA) and multiple sclerosis (MS), but this cytokine has also been associated with protection against bacterial infections (137). IL-17 could be synthesized more rapidly by natural killer T cells (NKT cells), $\gamma \delta \mathrm{T}$ cells and innate lymphoid cells than Th17 cells due to ROR $\gamma \mathrm{t}$ expressed on these cell types (138). The roles of IL-17 and IL-23 in the host response against the pulmonary fungal infection have been of focus recently. In the airway lesions, IL17 potently regulates neutrophil recruitment and homeostasis together with IL-23 $(139,140)$. Intriguingly, in the A. fumigatus model of pulmonary fungal infection via the intranasal route, IL-17 and IL-23 are highlighted with a regulatory role, by restricting the IL-12-IFN- $\gamma$ mediated Th1 protective response or even by impairing the antifungal immune resistance (141).
Thus, the multi-faceted roles of host inflammation are that it is not only critically responsible for the antifungal immunity, but that is also negatively controls proper immune reactions or even worsens fungal diseases when the balance between protection and pathogenesis is dysregulated in certain milieu.

\section{Type I and Type II Interferons}

IFN- $\alpha / \beta$, as typical type I interferons, are produced by various cell types after many stimuli, especially viruses. Through binding to a specific IFN- $\alpha / \beta$ receptor termed IFNAR (IFN- $\alpha / \beta$ R), downstream IFN-stimulated genes (ISGs) can be induced. IFNAR is composed of two subtypes IFNAR1 and IFNAR2. Canonical type I IFN signaling triggers the Janus kinase (JAK)-signal transducer and activator of the transcription (STAT) pathway, resulting in ISG gene expression (142). Up to now, limited information is known about their roles in non-viral infections such as a pulmonary fungal infection (143). Nonetheless, signaling of type I interferons in the host defense against $C$. neoformans was addressed in a recent study. Using IFNAR1 defected mice (IFNAR1 KO), the authors found an increased fungal clearance by, with enhanced Th2 and Th17 responses after infection compared with control animals. In addition, IFNAR1 KO mice exhibited significantly higher MUC5AC expression in bronchoepithelial cells. Therefore, type I interferons might negatively control the early host defense to a fungal infection (144). In contrast, another group reported that mice lacking either the IFNAR or IFN- $\beta$ succumbed to unrestrained pneumonia and encephalitis after an intratracheal or i.v. challenge with $C$. neoformans with increased Th2 cytokines IL-4/IL-10/IL-13, but reduced TNF$\alpha$, IFN- $\gamma$, iNOS, and CXCL10, suggesting that the protection by the type I IFN signaling is associated with type I cytokine polarization (145). In the case of Aspergillus infection, its conidia mainly induce the IFN- $\beta$ signaling in respiratory epithelial cells. Resting conidia can be sensed by differentiated human bronchial epithelial cells (HBECs), leading to the production of IFN- $\beta$-inducible genes such as IP-10 (CXCL10). Activated $\mathrm{T}$ cells could be further regulated by IP-10 (146). Inhibition on the IFN- $\beta$ signaling mediators such as RIP-1 (Receptorinteracting protein 1 ) and TBK-1 (TANK-binding kinase-1) by resveratrol could reduce the IFN-B/IP-10 expression (147). On the other hand, Th1 type cytokine IFN- $\gamma$ has been proven effective in clearing C. neoformans infection. Recombinant IFN- $\gamma$ administration reduces the fungal burden and increases survival rates, reinforcing the efficiency of fungicidal amphotericin $B$ $(148,149)$. Pulmonary cytokine analysis demonstrated that there was a Th1-type pro-inflammatory cytokines bias, rather than Th2-type cytokines expression, in mice challenged with the IFN$\gamma$ releasing C. neoformans strain, compared to wild-type straintreated mice (150).

\section{Classical Cytokines and Chemokines: IL-6, IL-8 (KC), TNF- $\alpha$, GM-CSF}

Pro-inflammatory cytokines such as IL-6, IL-8 (KC), TNF$\alpha$, and GM-CSF are essential factors in innate immunity. In hematological patients combined with IPA, levels of interleukin (IL)-6 and IL-8 are elevated in both serum and bronchoalveolar 
lavage fluid (BALF) (151). Circulating IL-6 is able to induce acute phase responses to control local or systemic acute inflammation with its anti-inflammatory activity (152). IL-6 increases Aspergillus-induced IL-17 production from healthy and hematological controls, but not in IPA patients with impaired $\mathrm{T}$ cell responsiveness to IL-6 (153). The interleukin (IL)-8 as CXC chemokine (CXCL8) is produced from respiratory epithelial cells via the PI3K and MAPK pathways, instead of the TLR-MyD88 pathway, upon Aspergillus infection (130), similar to other CXC chemokines such as KC (keratinocyte-derived chemokine, CXCL1, specific for mice, it is the counter chemokine for IL-8 in humans) and MIP-2 (macrophage inflammatory protein 2, CXCL2/3). Markedly higher levels of KC and MIP2 were observed in the lungs of animals transiently depleted of neutrophils upon challenge with AF; and the lung-specific overexpression of KC improved the outcome of mice in IPA by augmenting the host defense against Aspergillus $(154,155)$. Transcriptionally, proteases derived from A. fumigatus elicit cytokine production in human alveolar type II epithelium-like cells by enhancing IL-6 and IL-8 mRNA levels (156). However, some other study showed that limited levels of these cytokines (IL-6 and IL-8) are synthesized by A549 cells after contacting A. fumigatus, resulting in impaired recruitment of leukocytes to the lesion sites and pathogen escape from immune defense (157). There is also a study showing that $A$. fumigatus induced an acute inflammation regulated by neutrophils with pro-inflammatory cytokines (TNF- $\alpha$, GM-CSF, and IL-1 $\beta$ ) and chemokines (MIP1a, MCP-1 and MIP-2) induction during the peak of infection in the lung, neutralizing TNF- $\alpha$ or GM-CSF decreased neutrophil influx and delayed fungal clearance (158). As for TNF- $\alpha$, it enhances host responses to A. fumigatus, and inhibition on its function might increase susceptibility to aspergillosis (159). In a cytokine network assay in the lungs of immunocompetent mice, endogenous TNF- $\alpha$, IFN- $\gamma$, IL-18, IL-12 are immunoreactive with antifungal activity in response to inhaled A. fumigatus (160). In addition, Granulocyte-macrophage colony-stimulating factor (GM-CSF) is a pleiotropic hematopoietic cytokine regulating the myeloid cell host response. The receptor of GM-CSF (GM-CSFR/Csf2r) is composed of GM-CSFR $\alpha / \mathrm{Csf2ra}$ and GMCSFR $\beta / C s f 2 r b$ (161). Mice lacking the GM-CSF receptor $\beta$ chain (GM-CSFR $\beta$ ) were susceptible with a higher mortality to $A$. fumigatus conidia infection in the lung, illustrating the functional role of GM-CSFR $\beta$ signaling against inhaled A. fumigatus (162). In response to C. neoformans yeast cells or the major capsular polysaccharide-glucuronoxylomannan (GXM), human polymorphonuclear leukocytes from normal subjects can release inflammatory cytokines (163). Of note, macrophage polarization status is critical for the control of C. neoformans infection, and IFN- $\gamma$ and IL- 4 are responsible for the M1/2 polarization associated fungicidal activity. This implies the communication of cell mediated immunity and cytokine mediated immunity (164). Considering clinical applications and translational medicine, targeting the cytokines might be a useful intervention approach for antifungal therapy. To this end, a fluoroquinolone drug moxifloxacin conferred protective effect on human monocytes infected with A. fumigatus by inhibiting inflammatory cytokine productions via NF- $\kappa B$ and MAPK inactivation (165).

\section{Secreted Soluble Proteins in the Lung}

Besides the cytokine/chemokines produced by infected immune cells, the innate immune system can form another barrier on the airway surface upon inhalation of fungal pathogens. Numerous soluble peptides and proteins in this barrier confer antimicrobial activity. This is fulfilled by lysozyme, lactoferrin, secretory leukocyte proteases, secretory phospholipase A2, defensins, and cathelicidins, which are largely secreted by cells in the airway submucosal glands or epithelial cells. Just like antimicrobial peptides (AMPs) in the gut, these soluble effector molecules have been shown to eliminate a spectrum of microorganisms with neutralizing, opsonization, antibiotic or direct killing activities $(166,167)$.

\section{Collectin}

The human collectin family (collagen-like or C-type lectin) include MBL (Mannan binding lectin) and pulmonary surfactant proteins $\mathrm{A}$ to $\mathrm{D}$, which are important innate immune mediators for antifungal defense (168). The functions of collectins encompass opsonization, inflammation regulation, and the direct clearance of pathogens (169). A previous study has demonstrated the protective effect of MBL in a mouse model of aspergillosis (170). In the airways, surfactant proteins render immune protection against fungal accumulation and then clearance by phagocytosis (171). Among them, SP-A in respiratory tract binds to C. neoformans without enhancing phagocytosis, while SPD may play an essential role at the early stage of infection with an increased rate of uptake and phagocytosis. Thus, a greater number of phagocytosed C. neoformans cells in wildtype mice than in SP-D KO mice were observed. However, SP$\mathrm{D}$ enhances fungal survival in macrophages in vitro, and mice lacking SP-D are protected in vivo $(171,172)$. The reason for these opposing findings awaits further investigation. Collectins, ficolins, and pentraxins are circulating proteins which could serve as opsonins (173). Type II alveolar epithelial cells could secrete $\mathrm{H}$-Ficolin as innate immune opsonin to involve in pulmonary defenses against fungal infection. Silke Schelenz1s' group found that $\mathrm{H}$-ficolin was involved in A. fumigatus defense through the activation of the lectin complement pathway, highlighting the interaction between host and fungus and the modulation of the immune response by ficolin (174). In addition, another human serum opsonin, L-ficolin was detected in the bronchoalveolar lavage (BAL) fluid from patients with a fungal infection. Lficolin opsonization increased IL-8 production from A549 cells and enhanced conidial uptake and the killing of A. fumigatus by macrophages and neutrophils, with a reduced release of inflammatory cytokines (175).

\section{Defensin and Lysozyme}

The release of inflammatory mediators such as AMPs from epithelial cells is a critical step for the generation of protective activities, including inflammatory cell recruitment and generation of direct antimicrobial factors. Defensins, especially the b-defensin, are one type of AMP that are characterized by the presence of $b$-sheets stabilized by two disulfide bonds. In a study on HBECs, exposure to A. fumigatus led to the expression of b-defensin2 and b-defensin9 (hBD2 and hBD9) 
genes, suggesting that AMPs from respiratory epithelium are involved in host response during Aspergillus infection (176). In addition, as one of the most abundant antimicrobial proteins in the airway, lysozyme is a small enzyme synthesized by epithelium as well as resident macrophages in human lung tissues, which contributes to hyphal disruption of A. fumigatus $(177,178)$. In mice, two isoforms of lysozyme are identified: lysozyme $\mathrm{P}$ is expressed on Paneth cells in the small intestine and lysozyme $\mathrm{M}$ is predominantly expressed on alveolar macrophages, alveolar type II epithelial cells, and bronchoalveolar lavage fluid (BALF) in the lung $(179,180)$. However, whether lysozyme $\mathrm{M}$ renders protection against pathogenic fungi in the lung remains uncertain. The results of previous studies indicate that defensins and lysozymes might be involved in host defense against respiratory fungal infections.

\section{Calcineurin Signaling}

Calcineurin and related pathways are implicated in the controls of hyphal synthesis, morphological character, and virulence in $A$. fumigatus. Calcineurin is a heterodimer consisting of catalytic subunit $\mathrm{A}$ and $\mathrm{Ca}^{2+} /$ calmodulin binding unit, a mutant of $A$. fumigatus with depleted calcineurin A catalytic subunit displayed deficiency in morphology and decreased filamentation (181183). Meanwhile, calcineurin mutant with decreased beta-glucan amounts promoted the fungicidal activity of cell wall inhibitors, implying that targeting calcineurin can be a potential synergistic therapy with other fungicides against A. fumigatus (184). The growth of $C$. neoformans was sensitive to CsA and FK506 which mediates the signal transduction on $\mathrm{Ca}^{2+}$-regulated protein phosphatase calcineurin and the Calcineurin mutant strains failed to be infectious in an animal model of cryptococcosis in the brain, suggesting that calcineurin is necessary for pathogenicity of C. neoformans (185) (Figure 4B). In addition, host calcineurin signaling is also important for host immune responses to fungal infection, for instance, the intervention of neutrophils ability on Aspergillus species germination was inhibited in hematopoietic stem cell transplant (HSCT) individuals and this impairment was partly attributed to the administration of calcineurin inhibitors (186), suggesting that calcineurin signaling might affect neutrophils activity against Aspergillus, especially in immunocompromised hosts. Besides the neutrophils, calcineurin signaling has also been associated with macrophages. It was reported that calcineurin inhibitor tacrolimus impaired macrophage immune responses and the clearance of the major mold pathogen A. fumigatus from the airway, possibly due to the inhibition on A. fumigatus-induced phagosomal TLR9-BTKCalcineurin-NFAT cascades independent of MyD88, and NFAT collaborating with NF- $\kappa$ B contributed to TNF- $\alpha$ production in primary alveolar macrophages (187). By targeting host and pathogen calcineurin signaling, cyclosporine (CsA) can be used as both an immunosuppressive drug and antimicrobial agent, which inhibits the protein phosphatase calcineurin. However, inhibition on host calcineurin or its downstream calcineurinNFAT pathway by CsA, can protect transplant recipients from severe transplant rejection, and it might at the same time increase host immune defects leading to organ transplant-related invasive aspergillosis. Interestingly, the diversity of immunosuppressants determined different outcomes in transplant patients but the death rate appeared to be lower in individuals who received the calcineurin-inhibitors (188), the precise mechanisms on the host calcineurin signaling in cryptococcosis remains to be investigated.

\section{Molecules Mediating Autophagy During Fungal Infection}

Fungi often infect mammalian hosts where they interplay with each other: extracellular pathogens could be cleared by immune cells via a phagocytosis process, however, pathogens could also induce autophagy which is a lysosomal degradation process essential for host cell survival and homeostasis (189-192). The autophagy machinery may functionally protect against the threats of infection by eliminating invading pathogens $(193,194)$, specifically, LC3-associated phagocytosis (LAP) in phagocytes is a non-canonical autophagy pattern, and phagosomes with a single-membrane formation followed by a clearance of engulfed pathogens is required in this process. This LAP is started by the sensing of pathogens via PRRs and the LC3 recruitment to the phagosomal membrane. This precise xenophagy or LAP is utilized for the host defense against invading fungi (195-197).

In both host cells and in yeast cells, the extent of autophagy is critical for the control of pathogens as well as the survival of immune cells, mainly because autophagy is associated with cell programmed necrosis and apoptosis (191). In a reported study, the autophagy in macrophages with response to C. neoformans was assessed and the non-activated bone marrow derived macrophages (BMDMs) from Atg5 (Autophagy-related gene 5) knockout mice restricted $C$. neoformans growth with fungistatic activity; and in vivo, mice with myeloid depletion of Atg5 consistently displayed reduced susceptibility to C. neoformans (198). LAP is essential for host anti-fungal responses. Recent evidence indicated that LAP could be blocked by A. fumigatus cell wall melanin for its pathogenicity enhancement $(199,200)$. Canonical autophagy molecules are equally of importance for LAP, for instance, beclin-1 in the PI3K pathway is recruited to autophagosome after internalization of zymosan by phagocytes. The autophagy protein ATG7 is also important for LAP, because the loss of this molecule would lead to the abolishment of LC3 recruitment and reduced clearance of internalized pathogens and apoptotic cells $(201,202)$. The recently identified autophagy protein Rubicon (RUN domain protein as Beclin-1 interacting and cysteine rich containing) was essential for LAP but not autophagy induction, mediating clearance of A fumit (203). In addition, NADPH regulated ROS is required for LC3 recruitment (200).

Interestingly, the Atg genes in C. neoformans are also involved in the pathogenic mechanisms of infection, for instance, $C$. neoformans with an Atg7 mutant conferred lower survival but higher susceptibility to the killing machinery of different host phagocytes in mice with a pulmonary infection (204). It was proven that PI3K signaling with a defective formation of Atg8 labeled vesicles within the C. neoformans exhibited a dramatic virulence attenuation in a murine infection model (205) (Figure 4B). 


\section{PERSPECTIVE}

In this review, we summarized the cellular and molecular mechanisms of the host defense against pathogenic fungal infections in the lung. Regarding cells, innate immune cells including macrophages, neutrophils as well as DCs are the first line cells in the host response to a fungal invasion; adaptive $\mathrm{T}$ lymphocytes are of importance to restrain fungal expansion; and the NK cells are responsible for the direct killing of fungal pathogens by its cytotoxicity. In regards to signaling molecules, receptors-adaptors-transcriptional factors form the cascade to maintain homeostasis upon fungal infection. Cytokine production is essential in the microenvironment as they can link intercellular communication via cytokine receptors. However, more mechanisms remain to be studied. Phagocytosis regulation, autophagy, miRNA/lncRNA or ROS signaling in pathogenic fungal infections are all currently understudied. Moreover, the identification of novel genes and pathways via high throughput screening or sequencing and further functional studies are still required to elucidate the

\section{REFERENCES}

1. Latge JP. Aspergillus fumigatus and aspergillosis. Clin Microbiol Rev. (1999) 12:310-50. doi: 10.1128/CMR.12.2.310

2. Yao Z, Liao W. Fungal respiratory disease. Curr Opin Pulm Med. (2006) 12:222-7. doi: 10.1097/01.mcp.0000219272.57933.01

3. Carvalho A, Cunha C, Iannitti RG, De Luca A, Giovannini G, Bistoni F, et al. Inflammation in aspergillosis: the good, the bad, and the therapeutic. Ann N Y Acad Sci. (2012) 1273:52-9. doi: 10.1111/j.1749-6632.2012.06754.x

4. Chayakulkeeree M, Perfect JR. Cryptococcosis. Infect Dis Clin North Am. (2006) 20:507-44, v-vi. doi: 10.1016/j.idc.2006.07.001

5. Kronstad JW, Attarian R, Cadieux B, Choi J, D'Souza CA, Griffiths EJ, et al. Expanding fungal pathogenesis: Cryptococcus breaks out of the opportunistic box. Nat Rev Microbiol. (2011) 9:193-203. doi: 10.1038/nrmicro2522

6. Mitchell TG, Perfect JR. Cryptococcosis in the era of AIDS-100 years after the discovery of Cryptococcus neoformans. Clin Microbiol Rev. (1995) 8:515-48. doi: 10.1128/CMR.8.4.515

7. Udwadia ZF, Doshi AV, Bhaduri AS. Pneumocystis pneumonia. NEngl J Med. (2004) 351:1262-3. doi: 10.1056/NEJM200409163511222

8. Lortholary O, Denning DW, Dupont B. Endemic mycoses: a treatment update. J Antimicrob Chemother. (1999) 43:321-31. doi: 10.1093/jac/43.3.321

9. Wheat J. Endemic mycoses in AIDS: a clinical review. Clin Microbiol Rev. (1995) 8:146-59. doi: 10.1128/CMR.8.1.146

10. Bellocchio S, Moretti S, Perruccio K, Fallarino F, Bozza S, Montagnoli C, et al. TLRs govern neutrophil activity in aspergillosis. J Immunol. (2004) 173:7406-15. doi: 10.4049/jimmunol.173.12.7406

11. José RJ, Brown JS. Opportunistic and fungal infections of the lung. Medicine. (2012) 40:335-9. doi: 10.1016/j.mpmed.2012.03.013

12. McMath WF, Hussain KK. Cryptococcal meningo-encephalitis. Br Med J. (1961) 2:91-3. doi: 10.1136/bmj.2.5244.91

13. Kawai T, Akira S. The role of pattern-recognition receptors in innate immunity: update on Toll-like receptors. Nat Immunol. (2010) 11:373-84. doi: $10.1038 /$ ni. 1863

14. Takeuchi O, Akira S. Pattern recognition receptors and inflammation. Cell. (2010) 140:805-20. doi: 10.1016/j.cell.2010.01.022

15. Howard SJ, Cerar D, Anderson MJ, Albarrag A, Fisher MC, Pasqualotto AC, et al. Frequency and evolution of Azole resistance in Aspergillus fumigatus associated with treatment failure. Emerg Infect Dis. (2009) 15:1068-76. doi: 10.3201/eid1507.090043

16. Lamoth F, Juvvadi PR, Soderblom EJ, Moseley MA, Asfaw YG, Steinbach WJ. Identification of a key lysine residue in heat shock protein 90 required host defense mechanisms against infectious fungal pathogens in the lung.

\section{AUTHOR CONTRIBUTIONS}

ZL and GM conceived, wrote, and edited the manuscript. GL and GM checked and approved the final version of the manuscript.

\section{FUNDING}

This work was supported by funding to the Postdoc program by the Joint Center for Infection and Immunity between Guangzhou Women and Children's Medical Center and the Institute Pasteur of Shanghai, Chinese Academy of Science. The lab of GM is supported by funding from the National Key Basic Research Programs of China (2015CB554302, 2016YFE0133500, 2018YFA0507300), Natural Science Foundation of China (81830049, 81761128012, 31570895) and Strategic Priority Research Program Grant (XDB29030303) of Chinese Academy of Sciences.

for azole and echinocandin resistance in Aspergillus fumigatus. Antimicrob Agents Chemother. (2014) 58:1889-96. doi: 10.1128/AAC.02286-13

17. Yaguchi T. The genus Aspergillus. Med Mycol J. (2011) 52:193-7. doi: $10.3314 / \mathrm{mmj} .52 .193$

18. Ibrahim-Granet O, Philippe B, Boleti H, Boisvieux-Ulrich E, Grenet $\mathrm{D}$, Stern M, et al. Phagocytosis and intracellular fate of Aspergillus fumigatus conidia in alveolar macrophages. Infect Immun. (2003) 71:891903. doi: 10.1128/IAI.71.2.891-903.2003

19. Mouyna I, Sarfati J, Recco P, Fontaine T, Henrissatz B, Latge JP. Molecular characterization of a cell wall-associated beta(13)endoglucanase of Aspergillus fumigatus. Med Mycol. (2002) 40:455-64. doi: 10.1080/mmy.40.5.455.464

20. Bernard M, Mouyna I, Dubreucq G, Debeaupuis JP, Fontaine T, Vorgias C, et al. Characterization of a cell-wall acid phosphatase (PhoAp) in Aspergillus fumigatus. Microbiology. (2002) 148(Pt 9):2819-29. doi: 10.1099/00221287-148-9-2819

21. Latge JP. The pathobiology of Aspergillus fumigatus. Trends Microbiol. (2001) 9:382-9. doi: 10.1016/S0966-842X(01)02104-7

22. Blasi E, Barluzzi R, Mazzolla R, Bistoni F. Differential host susceptibility to intracerebral infections with Candida albicans and Cryptococcus neoformans. Infect Immun. (1993) 61:3476-81.

23. Lundgren B, Lipschik GY, Kovacs JA. Purification and characterization of a major human Pneumocystis carinii surface antigen. J Clin Invest. (1991) 87:163-70. doi: 10.1172/JCI114966

24. Kling HM, Shipley TW, Patil SP, Kristoff J, Bryan M, Montelaro RC, et al. Relationship of Pneumocystis jiroveci humoral immunity to prevention of colonization and chronic obstructive pulmonary disease in a primate model of HIV infection. Infect Immun. (2010) 78:4320-30. doi: 10.1128/IAI.00507-10

25. Morris A, Netravali M, Kling HM, Shipley T, Ross T, Sciurba FC, et al. Relationship of pneumocystis antibody response to severity of chronic obstructive pulmonary disease. Clin Infect Dis. (2008) 47:e64-8. doi: 10.1086/591701

26. Queiroz-Telles F, Fahal AH, Falci DR, Caceres DH, Chiller T, Pasqualotto AC. Neglected endemic mycoses. Lancet Infect Dis. (2017) 17:e367-77. doi: 10.1016/S1473-3099(17)30306-7

27. Hage CA, Knox KS, Wheat LJ. Endemic mycoses: overlooked causes of community acquired pneumonia. Respir Med. (2012) 106:769-76. doi: 10.1016/j.rmed.2012.02.004

28. Malcolm TR, Chin-Hong PV. Endemic mycoses in immunocompromised hosts. Curr Infect Dis Rep. (2013) 15:536-43. doi: 10.1007/s11908-013-0387-4 
29. Le T, Wolbers M, Chi NH, Quang VM, Chinh NT, Lan NP, et al. Epidemiology, seasonality, and predictors of outcome of AIDS-associated Penicillium marneffei infection in Ho Chi Minh City, Viet Nam. Clin Infect Dis. (2011) 52:945-52. doi: 10.1093/cid/cir028

30. Galgiani JN, Catanzaro A, Cloud GA, Johnson RH, Williams PL, Mirels LF, et al. Comparison of oral fluconazole and itraconazole for progressive, nonmeningeal coccidioidomycosis. A randomized, doubleblind trial. Mycoses Study Group. Ann Intern Med. (2000) 133:676-86. doi: 10.7326/0003-4819-133-9-200011070-00009

31. Brummer E, Castaneda E, Restrepo A. Paracoccidioidomycosis: an update. Clin Microbiol Rev. (1993) 6:89-117. doi: 10.1128/CMR.6.2.89

32. Boulware DR. Cryptococcus: from human pathogen to model yeast. Lancet Infect Dis. (2011) 11:434. doi: 10.1016/S1473-3099(11)70140-2

33. Pappalardo MC, Melhem MS. Cryptococcosis: a review of the Brazilian experience for the disease. Rev Inst Med Trop. (2003) 45:299-305. doi: 10.1590/S0036-46652003000600001

34. Sugar AM, Stern JJ, Dupont B. Overview: treatment of cryptococcal meningitis. Rev Infect Dis. (1990) 12(Suppl. 3):S338-48. doi: 10.1093/clinids/12.Supplement_3.S338

35. Park BJ, Wannemuehler KA, Marston BJ, Govender N, Pappas PG, Chiller TM. Estimation of the current global burden of cryptococcal meningitis among persons living with HIV/AIDS. AIDS. (2009) 23:525-30. doi: 10.1097/QAD.0b013e328322ffac

36. Charlier C, Nielsen K, Daou S, Brigitte M, Chretien F, Dromer F. Evidence of a role for monocytes in dissemination and brain invasion by Cryptococcus neoformans. Infect Immun. (2009) 77:120-7. doi: 10.1128/IAI.01065-08

37. Kim KS. Mechanisms of microbial traversal of the blood-brain barrier. Nat Rev Microbiol. (2008) 6:625-34. doi: 10.1038/nrmicro1952

38. Speed B, Dunt D. Clinical and host differences between infections with the two varieties of Cryptococcus neoformans. Clin Infect Dis. (1995) 21:28-34. doi: 10.1093/clinids/21.1.28

39. Sorrell TC, Ellis DH. Ecology of Cryptococcus neoformans. Rev Iberoam Micol. (1997) 14:42-3.

40. Kidd SE, Hagen F, Tscharke RL, Huynh M, Bartlett KH, Fyfe M, et al. A rare genotype of Cryptococcus gattii caused the cryptococcosis outbreak on Vancouver Island (British Columbia, Canada). Proc Natl Acad Sci USA. (2004) 101:17258-63. doi: 10.1073/pnas.0402981101

41. Jarvis JN, Boulle A, Loyse A, Bicanic T, Rebe K, Williams A, et al. High ongoing burden of cryptococcal disease in Africa despite antiretroviral roll out. AIDS. (2009) 23:1182-3. doi: 10.1097/QAD.0b013e32832be0fc

42. Chuck SL, Sande MA. Infections with Cryptococcus neoformans in the acquired immunodeficiency syndrome. N Engl J Med. (1989) 321:794-9. doi: 10.1056/NEJM198909213211205

43. Meyohas MC, Roux P, Bollens D, Chouaid C, Rozenbaum W, Meynard JL, et al. Pulmonary cryptococcosis: localized and disseminated infections in 27 patients with AIDS. Clin Infect Dis. (1995) 21:628-33. doi: 10.1093/clinids/21.3.628

44. Xie S, Sao R, Braun A, Bottone EJ. Difference in Cryptococcus neoformans cellular and capsule size in sequential pulmonary and meningeal infection: a postmortem study. Diagn Microbiol Infect Dis. (2012) 73:49-52. doi: 10.1016/j.diagmicrobio.2012.01.008

45. Silva EG, Paula CR, de Assis Baroni F, Gambale W. Voriconazole, combined with amphotericin $B$, in the treatment for pulmonary cryptococcosis caused by C. neoformans (serotype A) in mice with severe combined immunodeficiency (SCID). Mycopathologia. (2012) 173:445-9. doi: 10.1007/s11046-011-9499-2

46. Kiertiburanakul S, Wirojtananugoon S, Pracharktam R, Sungkanuparph S. Cryptococcosis in human immunodeficiency virus-negative patients. Int $J$ Infect Dis. (2006) 10:72-8. doi: 10.1016/j.ijid.2004.12.004

47. Severo CB, Xavier MO, Gazzoni AF, Severo LC. Cryptococcosis in children. Paediatr Respir Rev. (2009) 10:166-71. doi: 10.1016/j.prrv.2009. 06.009

48. Denning DW. Epidemiology and pathogenesis of systemic fungal infections in the immunocompromised host. J Antimicrob Chemother. (1991) 28(Suppl. B):1-16. doi: 10.1093/jac/28.suppl_B.1

49. Marr KA, Carter RA, Crippa F, Wald A, Corey L. Epidemiology and outcome of mould infections in hematopoietic stem cell transplant recipients. Clin Infect Dis. (2002) 34:909-17. doi: 10.1086/339202
50. Saral R. Candida and Aspergillus infections in immunocompromised patients: an overview. Rev Infect Dis. (1991) 13:487-92. doi: $10.1093 /$ clinids/13.3.487

51. Warris A, Bjorneklett A, Gaustad P. Invasive pulmonary aspergillosis associated with infliximab therapy. N Engl J Med. (2001) 344:1099-100. doi: 10.1056/NEJM200104053441415

52. Saag MS, Graybill RJ, Larsen RA, Pappas PG, Perfect JR, Powderly WG, et al. Practice guidelines for the management of cryptococcal disease. Infectious Diseases Society of America. Clin Infect Dis. (2000) 30:710-8. doi: $10.1086 / 313757$

53. Maesaki S, Kawamura S, Miyazaki Y, Tomono K, Tashiro T, Kohno S. Effect of sequential combination of amphotericin B and azole antifungal agents against Aspergillus fumigatus. J Infect Chemother. (1999) 5:125-9. doi: $10.1007 /$ s101560050021

54. Manavathu EK, Ramesh MS, Baskaran I, Ganesan LT, Chandrasekar PH. A comparative study of the post-antifungal effect (PAFE) of amphotericin B, triazoles and echinocandins on Aspergillus fumigatus and Candida albicans. J Antimicrob Chemother. (2004) 53:386-9. doi: 10.1093/jac/dkh066

55. Pfaller MA. Antifungal drug resistance: mechanisms, epidemiology, and consequences for treatment. Am J Med. (2012) 125(Suppl. 1):S3-13. doi: 10.1016/j.amjmed.2011.11.001

56. Medzhitov R. Recognition of microorganisms and activation of the immune response. Nature. (2007) 449:819-26. doi: 10.1038/nature06246

57. Doering TL. How sweet it is! Cell wall biogenesis and polysaccharide capsule formation in Cryptococcus neoformans. Annu Rev Microbiol. (2009) 63:22347. doi: 10.1146/annurev.micro.62.081307.162753

58. Underhill DM, Ozinsky A. Phagocytosis of microbes: complexity in action. Annu Rev Immunol. (2002) 20:825-52. doi: 10.1146/annurev.immunol.20.103001.114744

59. Philippe B, Ibrahim-Granet O, Prevost MC, Gougerot-Pocidalo MA, Sanchez Perez M, Van der Meeren A, et al. Killing of Aspergillus fumigatus by alveolar macrophages is mediated by reactive oxidant intermediates. Infect Immun. (2003) 71:3034-42. doi: 10.1128/IAI.71.6.3034-3042.2003

60. Pandey A, Ding SL, Qin QM, Gupta R, Gomez G, Lin F, et al. Global reprogramming of host kinase signaling in response to fungal infection. Cell Host Microbe. (2017) 21:637-49 e6. doi: 10.1016/j.chom.2017.04.008

61. Mircescu MM, Lipuma L, van Rooijen N, Pamer EG, Hohl TM. Essential role for neutrophils but not alveolar macrophages at early time points following Aspergillus fumigatus infection. J Infect Dis. (2009) 200:647-56. doi: $10.1086 / 600380$

62. Cenci E, Mencacci A, Fe d'Ostiani C, Del Sero G, Mosci P, Montagnoli $\mathrm{C}$, et al. Cytokine- and $\mathrm{T}$ helper-dependent lung mucosal immunity in mice with invasive pulmonary aspergillosis. J Infect Dis. (1998) 178:1750-60. doi: $10.1086 / 314493$

63. Osterholzer JJ, Milam JE, Chen GH, Toews GB, Huffnagle GB, Olszewski MA. Role of dendritic cells and alveolar macrophages in regulating early host defense against pulmonary infection with Cryptococcus neoformans. Infect Immun. (2009) 77:3749-58. doi: 10.1128/IAI.00454-09

64. Steele C, Rapaka RR, Metz A, Pop SM, Williams DL, Gordon S, et al. The beta-glucan receptor dectin-1 recognizes specific morphologies of Aspergillus fumigatus. PLoS Pathog. (2005) 1:e42. doi: 10.1371/journal.ppat.0010042

65. Hestdal K, Ruscetti FW, Ihle JN, Jacobsen SE, Dubois CM, Kopp WC, et al. Characterization and regulation of RB6-8C5 antigen expression on murine bone marrow cells. J Immunol. (1991) 147:22-8.

66. Stephens-Romero SD, Mednick AJ, Feldmesser M. The pathogenesis of fatal outcome in murine pulmonary aspergillosis depends on the neutrophil depletion strategy. Infect Immun. (2005) 73:114-25. doi: 10.1128/IAI.73.1.114-125.2005

67. Taylor PR, Roy S, Leal SM Jr, Sun Y, Howell SJ, Cobb BA, et al. Activation of neutrophils by autocrine IL-17A-IL-17RC interactions during fungal infection is regulated by IL-6, IL-23, RORgammat and dectin-2. Nat Immunol. (2014) 15:143-51. doi: 10.1038/ni.2797

68. Gazendam RP, van Hamme JL, Tool AT, Hoogenboezem M, van den Berg JM, Prins JM, et al. Human neutrophils use different mechanisms to kill Aspergillus fumigatus conidia and hyphae: evidence from phagocyte defects. J Immunol. (2016) 196:1272-83. doi: 10.4049/jimmunol.1501811

69. Banchereau J, Steinman RM. Dendritic cells and the control of immunity. Nature. (1998) 392:245-52. doi: 10.1038/32588 
70. Zitvogel L. Dendritic and natural killer cells cooperate in the control/switch of innate immunity. J Exp Med. (2002) 195:F9-14. doi: 10.1084 /jem.20012040

71. Ramadan G. The proliferative response of $\mathrm{T}$ cells to Aspergillus antigen requires prior presentation on dendritic cells. Egypt J Immunol. (2004) 11:47-58.

72. Gafa V, Remoli ME, Giacomini E, Severa M, Grillot R, Coccia EM. Enhancement of anti-Aspergillus $\mathrm{T}$ helper type 1 response by interferonbeta-conditioned dendritic cells. Immunology. (2010) 131:282-8. doi: 10.1111/j.1365-2567.2010.03302.x

73. Bozza S, Perruccio K, Montagnoli C, Gaziano R, Bellocchio S, Burchielli $\mathrm{E}$, et al. A dendritic cell vaccine against invasive aspergillosis in allogeneic hematopoietic transplantation. Blood. (2003) 102:3807-14. doi: 10.1182/blood-2003-03-0748

74. Mezger M, Kneitz S, Wozniok I, Kurzai O, Einsele H, Loeffler J. Proinflammatory response of immature human dendritic cells is mediated by dectin-1 after exposure to Aspergillus fumigatus germ tubes. J Infect Dis. (2008) 197:924-31. doi: 10.1086/528694

75. Park SJ, Burdick MD, Mehrad B. Neutrophils mediate maturation and efflux of lung dendritic cells in response to Aspergillus fumigatus germ tubes. Infect Immun. (2012) 80:1759-65. doi: 10.1128/IAI.00097-12

76. Gafa V, Remoli ME, Giacomini E, Gagliardi MC, Lande R, Severa $\mathrm{M}$, et al. In vitro infection of human dendritic cells by Aspergillus fumigatus conidia triggers the secretion of chemokines for neutrophil and Th1 lymphocyte recruitment. Microbes Infect. (2007) 9:971-80. doi: 10.1016/j.micinf.2007.03.015

77. Vivier E, Tomasello E, Baratin M, Walzer T, Ugolini S. Functions of natural killer cells. Nat Immunol. (2008) 9:503-10. doi: 10.1038/ni1582

78. Mortha A, Diefenbach A. Natural killer cell receptor-expressing innate lymphocytes: more than just NK cells. Cell Mol Life Sci. (2011) 68:3541-55. doi: 10.1007/s00018-011-0803-6

79. Kelly MN, Zheng M, Ruan S, Kolls J, D’Souza A, Shellito JE. Memory $\mathrm{CD} 4+\mathrm{T}$ cells are required for optimal NK cell effector functions against the opportunistic fungal pathogen Pneumocystis murina. J Immunol. (2013) 190:285-95. doi: 10.4049/jimmunol.1200861

80. Schmidt S, Tramsen L, Hanisch M, Latge JP, Huenecke S, Koehl U, et al. Human natural killer cells exhibit direct activity against Aspergillus fumigatus hyphae, but not against resting conidia. J Infect Dis. (2011) 203:430-5. doi: 10.1093/infdis/jiq062

81. Morton CO, Bouzani M, Loeffler J, Rogers TR. Direct interaction studies between Aspergillus fumigatus and human immune cells; what have we learned about pathogenicity and host immunity? Front Microbiol. (2012) 3:413. doi: 10.3389/fmicb.2012.00413

82. Hidore MR, Nabavi N, Sonleitner F, Murphy JW. Murine natural killer cells are fungicidal to Cryptococcus neoformans. Infect Immun. (1991) 59:1747-54.

83. Wozniak KL, Ravi S, Macias S, Young ML, Olszewski MA, Steele C, et al. Insights into the mechanisms of protective immunity against Cryptococcus neoformans infection using a mouse model of pulmonary cryptococcosis. PLoS ONE. (2009) 4:e6854. doi: 10.1371/journal.pone.0006854

84. Koguchi Y, Kawakami K. Cryptococcal infection and Th1-Th2 cytokine balance. Int Rev Immunol. (2002) 21:423-38. doi: 10.1080/0883018 0213274

85. Romani L, Fallarino F, De Luca A, Montagnoli C, D’Angelo C, Zelante T, et al. Defective tryptophan catabolism underlies inflammation in mouse chronic granulomatous disease. Nature. (2008) 451:211-5. doi: 10.1038/nature06471

86. Carvalho A, De Luca A, Bozza S, Cunha C, D’Angelo C, Moretti S, et al. TLR3 essentially promotes protective class I-restricted memory CD8(+) T-cell responses to Aspergillus fumigatus in hematopoietic transplanted patients. Blood. (2012) 119:967-77. doi: 10.1182/blood-2011-06-362582

87. Bals R. Epithelial antimicrobial peptides in host defense against infection. Respir Res. (2000) 1:141-50. doi: 10.1186/rr25

88. Paris S, Boisvieux-Ulrich E, Crestani B, Houcine O, Taramelli D, Lombardi $\mathrm{L}$, et al. Internalization of Aspergillus fumigatus conidia by epithelial and endothelial cells. Infect Immun. (1997) 65:1510-4.

89. de Luca A, Bozza S, Zelante T, Zagarella S, D’Angelo C, Perruccio K, et al. Non-hematopoietic cells contribute to protective tolerance to Aspergillus fumigatus via a TRIF pathway converging on IDO. Cell Mol Immunol. (2010) 7:459-70. doi: $10.1038 / \mathrm{cmi} .2010 .43$
90. Cunha C, Carvalho A, Esposito A, Bistoni F, Romani L. DAMP signaling in fungal infections and diseases. Front Immunol. (2012) 3:286. doi: 10.3389/fimmu.2012.00286

91. Barreto-Bergter E, Figueiredo RT. Fungal glycans and the innate immune recognition. Front Cell Infect Microbiol. (2014) 4:145. doi: 10.3389/fcimb.2014.00145

92. Taylor PR, Tsoni SV, Willment JA, Dennehy KM, Rosas M, Findon H, et al. Dectin-1 is required for beta-glucan recognition and control of fungal infection. Nat Immunol. (2007) 8:31-8. doi: 10.1038/ni1408

93. Sato K, Yang XL, Yudate T, Chung JS, Wu J, Luby-Phelps K, et al. Dectin-2 is a pattern recognition receptor for fungi that couples with the Fc receptor gamma chain to induce innate immune responses. J Biol Chem. (2006) 281:38854-66. doi: 10.1074/jbc.M606542200

94. Richardson MB, Williams SJ. MCL and Mincle: C-Type lectin receptors that sense damaged self and pathogen-associated molecular patterns. Front Immunol. (2014) 5:288. doi: 10.3389/fimmu.2014.00288

95. Svirshchevskaya E, Zubkov D, Mouyna I, Berkova N. Innate immunity and the role of epithelial barrier during Aspergillus fumigatus infection. Curr Immunol Rev. (2012) 8:254-61. doi: 10.2174/1573395128006 71985

96. Stappers MHT, Clark AE, Aimanianda V, Bidula S, Reid DM, Asamaphan P, et al. Recognition of DHN-melanin by a C-type lectin receptor is required for immunity to Aspergillus. Nature. (2018) 555:382-6. doi: 10.1038/nature 25974

97. Mansour MK, Schlesinger LS, Levitz SM. Optimal T cell responses to Cryptococcus neoformans mannoprotein are dependent on recognition of conjugated carbohydrates by mannose receptors. J Immunol. (2002) 168:2872-9. doi: 10.4049/jimmunol.168.6.2872

98. Mansour MK, Latz E, Levitz SM. Cryptococcus neoformans glycoantigens are captured by multiple lectin receptors and presented by dendritic cells. J Immunol. (2006) 176:3053-61. doi: 10.4049/jimmunol.176.5.3053

99. Balloy V, Si-Tahar M, Takeuchi O, Philippe B, Nahori MA, Tanguy $\mathrm{M}$, et al. Involvement of toll-like receptor 2 in experimental invasive pulmonary aspergillosis. Infect Immun. (2005) 73:5420-5. doi: 10.1128/IAI.73.9.5420-5425.2005

100. Bellocchio S, Montagnoli C, Bozza S, Gaziano R, Rossi G, Mambula SS, et al. The contribution of the Toll-like/IL-1 receptor superfamily to innate and adaptive immunity to fungal pathogens in vivo. J Immunol. (2004) 172:3059-69. doi: 10.4049/jimmunol.172.5.3059

101. Chignard M, Balloy V, Sallenave JM, Si-Tahar M. Role of toll-like receptors in lung innate defense against invasive aspergillosis. Distinct impact in immunocompetent and immunocompromized hosts. Clin Immunol. (2007) 124:238-43. doi: 10.1016/j.clim.2007.05.004

102. Netea MG, Ferwerda G, van der Graaf CA, Van der Meer JW, Kullberg BJ. Recognition of fungal pathogens by toll-like receptors. Curr Pharm Des. (2006) 12:4195-201. doi: 10.2174/138161206778743538

103. Suzuki N, Chen NJ, Millar DG, Suzuki S, Horacek T, Hara H, et al. IL-1 receptor-associated kinase 4 is essential for IL-18-mediated NK and Th1 cell responses. J Immunol. (2003) 170:4031-5. doi: 10.4049/jimmunol.170.8.4031

104. Bozza S, Zelante T, Moretti S, Bonifazi P, DeLuca A, D’Angelo C, et al. Lack of Toll IL-1R8 exacerbates Th17 cell responses in fungal infection. J Immunol. (2008) 180:4022-31. doi: 10.4049/jimmunol.180.6.4022

105. Vecchiarelli A, Pericolini E, Gabrielli E, Agostini M, Bistoni F, Nocentini G, et al. The GITRL-GITR system alters TLR-4 expression on DC during fungal infection. Cell Immunol. (2009) 257:13-22. doi: 10.1016/j.cellimm.2009.02.001

106. Nocentini G, Riccardi C. GITR: a multifaceted regulator of immunity belonging to the tumor necrosis factor receptor superfamily. Eur J Immunol. (2005) 35:1016-22. doi: 10.1002/eji.200425818

107. Medzhitov R, Preston-Hurlburt P, Kopp E, Stadlen A, Chen C, Ghosh S, et al. MyD88 is an adaptor protein in the hToll/IL-1 receptor family signaling pathways. Mol Cell. (1998) 2:253-8. doi: 10.1016/S1097-2765(00)80136-7

108. Bretz C, Gersuk G, Knoblaugh S, Chaudhary N, Randolph-Habecker J, Hackman RC, et al. MyD88 signaling contributes to early pulmonary responses to Aspergillus fumigatus. Infect Immun. (2008) 76:952-8. doi: 10.1128/IAI.00927-07

109. Gohda J, Matsumura T, Inoue J. Cutting edge: TNFR-associated factor (TRAF) 6 is essential for MyD88-dependent pathway but not toll/IL-1 
receptor domain-containing adaptor-inducing IFN-beta (TRIF)dependent pathway in TLR signaling. J Immunol. (2004) 173:2913-7. doi: 10.4049/jimmunol.173.5.2913

110. Muroi M, Tanamoto KI. TRAF6 distinctively mediates MyD88- and IRAK-1-induced activation of NF-kappaB. J Leukoc Biol. (2008) 83:702-7. doi: 10.1189/jlb.0907629

111. Gorjestani S, Darnay BG, Lin X. Tumor necrosis factor receptor-associated factor 6 (TRAF6) and TGFbeta-activated kinase 1 (TAK1) play essential roles in the C-type lectin receptor signaling in response to Candida albicans infection. J Biol Chem. (2012) 287:44143-50. doi: 10.1074/jbc.M112.414276

112. Hara $H$, Saito T. CARD9 versus CARMA1 in innate and adaptive immunity. Trends Immunol. (2009) 30:234-42. doi: 10.1016/j.it.2009.03.002

113. Kyrmizi I, Gresnigt MS, Akoumianaki T, Samonis G, Sidiropoulos P, Boumpas D, et al. Corticosteroids block autophagy protein recruitment in Aspergillus fumigatus phagosomes via targeting dectin-1/Syk kinase signaling. J Immunol. (2013) 191:1287-99. doi: 10.4049/jimmunol.1300132

114. Fang R, Tsuchiya K, Kawamura I, Shen Y, Hara H, Sakai S, et al. Critical roles of ASC inflammasomes in caspase-1 activation and host innate resistance to Streptococcus pneumoniae infection. J Immunol. (2011) 187:4890-9. doi: 10.4049/jimmunol.1100381

115. Skeldon A, Saleh M. The inflammasomes: molecular effectors of host resistance against bacterial, viral, parasitic, and fungal infections. Front Microbiol. (2011) 2:15. doi: 10.3389/fmicb.2011.00015

116. Munoz-Planillo R, Kuffa P, Martinez-Colon G, Smith BL, Rajendiran TM, Nunez G. $\mathrm{K}(+)$ efflux is the common trigger of NLRP3 inflammasome activation by bacterial toxins and particulate matter. Immunity. (2013) 38:1142-53. doi: 10.1016/j.immuni.2013.05.016

117. Katsnelson MA, Rucker LG, Russo HM, Dubyak GR. K+ efflux agonists induce NLRP3 inflammasome activation independently of Ca2+ signaling. J Immunol. (2015) 194:3937-52. doi: 10.4049/jimmunol.1402658

118. Gross CJ, Mishra R, Schneider KS, Medard G, Wettmarshausen J, Dittlein DC, et al. $\mathrm{K}(+)$ Efflux-independent NLRP3 inflammasome activation by small molecules targeting mitochondria. Immunity. (2016) 45:761-73. doi: 10.1016/j.immuni.2016.08.010

119. Huang Y, Hua M, Cui X. Fungal beta-Glucan Activates the NLRP3 inflammasome in human bronchial epithelial cells through ROS production. Inflammation. (2018) 41:164-73. doi: 10.1007/s10753-017-0674-6

120. Kumar H, Kumagai Y, Tsuchida T, Koenig PA, Satoh T, Guo Z, et al. Involvement of the NLRP3 inflammasome in innate and humoral adaptive immune responses to fungal beta-glucan. J Immunol. (2009) 183:8061-7. doi: 10.4049/jimmunol.0902477

121. Said-Sadier N, Padilla E, Langsley G, Ojcius DM. Aspergillus fumigatus stimulates the NLRP3 inflammasome through a pathway requiring ROS production and the Syk tyrosine kinase. PLOS ONE. (2010) 5:e10008. doi: 10.1371/journal.pone.0010008

122. Lamkanfi M, Malireddi RK, Kanneganti TD. Fungal zymosan and mannan activate the cryopyrin inflammasome. J Biol Chem. (2009) 284:20574-81. doi: 10.1074/jbc.M109.023689

123. Guo C, Chen M, Fa Z, Lu A, Fang W, Sun B, et al. Acapsular Cryptococcus neoformans activates the NLRP3 inflammasome. Microbes Infect. (2014) 16:845-54. doi: 10.1016/j.micinf.2014.08.013

124. Lei G, Chen M, Li H, Niu JL, Wu S, Mao L, et al. Biofilm from a clinical strain of Cryptococcus neoformans activates the NLRP3 inflammasome. Cell Res. (2013) 23:965-8. doi: 10.1038/cr.2013.49

125. Karki R, Man SM, Malireddi RKS, Gurung P, Vogel P, Lamkanfi M, et al. Concerted activation of the AIM2 and NLRP3 inflammasomes orchestrates host protection against Aspergillus infection. Cell Host Microbe. (2015) 17:357-68. doi: 10.1016/j.chom.2015.01.006

126. Gersuk GM, Underhill DM, Zhu L, Marr KA. Dectin-1 and TLRs permit macrophages to distinguish between different Aspergillus fumigatus cellular states. J Immunol. (2006) 176:3717-24. doi: 10.4049/jimmunol.176. 6.3717

127. Sun H, Xu XY, Tian XL, Shao HT, Wu XD, Wang Q, et al. Activation of NF- $\kappa \mathrm{B}$ and respiratory burst following Aspergillus fumigatus stimulation of macrophages. Immunobiology. (2014) 219:25-36. doi: 10.1016/j.imbio.2013.06.013

128. Pahl HL, Krauss B, Schulze-Osthoff K, Decker T, Traenckner EB, Vogt $\mathrm{M}$, et al. The immunosuppressive fungal metabolite gliotoxin specifically inhibits transcription factor NF-kappaB. J Exp Med. (1996) 183:1829-40. doi: 10.1084/jem.183.4.1829

129. Dubourdeau M, Athman R, Balloy V, Huerre M, Chignard M, Philpott DJ, et al. Aspergillus fumigatus induces innate immune responses in alveolar macrophages through the MAPK pathway independently of TLR2 and TLR4. J Immunol. (2006) 177:3994-4001. doi: 10.4049/jimmunol.177.6.3994

130. Balloy V, Sallenave JM, Wu Y, Touqui L, Latgé JP, Sitahar M, et al. Aspergillus fumigatus-induced IL-8 synthesis by respiratory epithelial cells is controlled by the PI3 kinase, p38 MAPK and ERK1/2 pathways and not by the TLR-MYD88 pathway. J Biol Chem. (2008) 283:30513-21. doi: 10.1074/jbc.M803149200

131. Shoham S, Huang C, Chen JM, Golenbock DT, Levitz SM. Toll-like receptor 4 mediates intracellular signaling without TNF-alpha release in response to Cryptococcus neoformans polysaccharide capsule. J Immunol. (2001) 166:4620-6. doi: 10.4049/jimmunol.166.7.4620

132. Garth JM, Reeder KM, Godwin MS, Mackel JJ, Dunaway CW, Blackburn JP, et al. IL-33 signaling regulates innate IL-17A and IL-22 production via suppression of prostaglandin E2 during lung fungal infection. J Immunol. (2017) 199:2140-8. doi: 10.4049/jimmunol.1602186

133. de Luca A, Smeekens SP, Casagrande A, Iannitti R, Conway KL, Gresnigt MS, et al. IL-1 receptor blockade restores autophagy and reduces inflammation in chronic granulomatous disease in mice and in humans. Proc Natl Acad Sci USA. (2014) 111:3526-31. doi: 10.1073/pnas.1322831111

134. Werner JL, Metz AE, Horn D, Schoeb TR, Hewitt MM, Schwiebert LM, et al. Requisite role for the dectin-1 beta-glucan receptor in pulmonary defense against Aspergillus fumigatus. J Immunol. (2009) 182:4938-46. doi: 10.4049/jimmunol.0804250

135. Caffrey AK, Lehmann MM, Zickovich JM, Espinosa V, Shepardson KM, Watschke CP, et al. IL-1alpha signaling is critical for leukocyte recruitment after pulmonary Aspergillus fumigatus challenge. PLoS Pathog. (2015) 11:e1004625. doi: 10.1371/journal.ppat.1004625

136. Gresnigt MS, Rosler B, Jacobs CW, Becker KL, Joosten LA, van der Meer JW, et al. The IL-36 receptor pathway regulates Aspergillus fumigatusinduced Th1 and Th17 responses. Eur J Immunol. (2013) 43:416-26. doi: 10.1002/eji.201242711

137. Stockinger B, Veldhoen M. Differentiation and function of Th17 T cells. Curr Opin Immunol. (2007) 19:281-6. doi: 10.1016/j.coi.2007.04.005

138. Cua DJ, Tato CM. Innate IL-17-producing cells: the sentinels of the immune system. Nat Rev Immunol. (2010) 10:479-89. doi: 10.1038/nri2800

139. Miyamoto M, Prause O, Sjostrand M, Laan M, Lotvall J, Linden A. Endogenous IL-17 as a mediator of neutrophil recruitment caused by endotoxin exposure in mouse airways. J Immunol. (2003) 170:4665-72. doi: 10.4049/jimmunol.170.9.4665

140. Stark MA, Huo Y, Burcin TL, Morris MA, Olson TS, Ley K. Phagocytosis of apoptotic neutrophils regulates granulopoiesis via IL-23 and IL-17. Immunity. (2005) 22:285-94. doi: 10.1016/j.immuni.2005.01.011

141. Zelante T, De Luca A, Bonifazi P, Montagnoli C, Bozza S, Moretti S, et al. IL-23 and the Th17 pathway promote inflammation and impair antifungal immune resistance. Eur J Immunol. (2007) 37:2695-706. doi: 10.1002/eji.200737409

142. Ivashkiv LB, Donlin LT. Regulation of type I interferon responses. Nat Rev Immunol. (2014) 14:36-49. doi: 10.1038/nri3581

143. Bogdan C, Mattner J, Schleicher U. The role of type I interferons in non-viral infections. Immunol Rev. (2004) 202:33-48. doi: 10.1111/j.0105-2896.2004.00207.x

144. Sato K, Yamamoto H, Nomura T, Matsumoto I, Miyasaka T, Zong $\mathrm{T}$, et al. Cryptococcus neoformans infection in mice lacking type I interferon signaling leads to increased fungal clearance and IL-4dependent mucin production in the lungs. PLoS ONE. (2015) 10:e0138291. doi: 10.1371/journal.pone.0138291

145. Biondo C, Midiri A, Gambuzza M, Gerace E, Falduto M, Galbo R, et al. IFNalpha/beta signaling is required for polarization of cytokine responses toward a protective type 1 pattern during experimental cryptococcosis. J Immunol. (2008) 181:566-73. doi: 10.4049/jimmunol.181.1.566

146. Dufour JH, Dziejman M, Liu MT, Leung JH, Lane TE, Luster AD. IFNgamma-inducible protein 10 (IP-10; CXCL10)-deficient mice reveal a role for IP-10 in effector T cell generation and trafficking. J Immunol. (2002) 168:3195-204. doi: 10.4049/jimmunol.168.7.3195 
147. Beisswenger C, Hess C, Bals R. Aspergillus fumigatus conidia induce interferon-beta signalling in respiratory epithelial cells. Eur Respir J. (2012) 39:411-8. doi: 10.1183/09031936.00096110

148. Joly V, Saint-Julien L, Carbon C, Yeni P. In vivo activity of interferongamma in combination with amphotericin B in the treatment of experimental cryptococcosis. J Infect Dis. (1994) 170:1331-4. doi: 10.1093/infdis/170.5.1331

149. Lutz JE, Clemons KV, Stevens DA. Enhancement of antifungal chemotherapy by interferon-gamma in experimental systemic cryptococcosis. J Antimicrob Chemother. (2000) 46:437-42. doi: 10.1093/jac/46.3.437

150. Wormley FL Jr, Perfect JR, Steele C, Cox GM. Protection against cryptococcosis by using a murine gamma interferon-producing Cryptococcus neoformans strain. Infect Immun. (2007) 75:1453-62. doi: 10.1128/IAI.00274-06

151. Heldt S, Eigl S, Prattes J, Flick H, Rabensteiner J, Pruller F, et al. Levels of interleukin (IL)-6 and IL-8 are elevated in serum and bronchoalveolar lavage fluid of haematological patients with invasive pulmonary aspergillosis. Mycoses. (2017) 60:818-25. doi: 10.1111/myc.12679

152. Xing Z, Gauldie J, Cox G, Baumann H, Jordana M, Lei XF, et al. IL-6 is an antiinflammatory cytokine required for controlling local or systemic acute inflammatory responses. J Clin Invest. (1998) 101:311-20. doi: $10.1172 / \mathrm{JCI} 1368$

153. Camargo JF, Bhimji A, Kumar D, Kaul R, Pavan R, Schuh A, et al. Impaired $\mathrm{T}$ cell responsiveness to interleukin- 6 in hematological patients with invasive aspergillosis. PLoS ONE. (2015) 10:e0123171. doi: 10.1371/journal.pone.0123171

154. Mehrad B, Strieter RM, Moore TA, Tsai WC, Lira SA, Standiford TJ. CXC chemokine receptor-2 ligands are necessary components of neutrophilmediated host defense in invasive pulmonary aspergillosis. J Immunol. (1999) 163:6086-94.

155. Mehrad B, Wiekowski M, Morrison BE, Chen SC, Coronel EC, Manfra DJ, et al. Transient lung-specific expression of the chemokine KC improves outcome in invasive aspergillosis. Am J Respir Crit Care Med. (2002) 166:1263-8. doi: 10.1164/rccm.200204-367OC

156. Borger P, Koeter GH, Timmerman JA, Vellenga E, Tomee JF, Kauffman HF. Proteases from Aspergillus fumigatus induce interleukin (IL)-6 and IL8 production in airway epithelial cell lines by transcriptional mechanisms. $J$ Infect Dis. (1999) 180:1267-74. doi: 10.1086/315027

157. Zhang Z, Liu R, Noordhoek JA, Kauffman HF. Interaction of airway epithelial cells (A549) with spores and mycelium of Aspergillus fumigatus. J Infect. (2005) 51:375-82. doi: 10.1016/j.jinf.2004.12.012

158. Schelenz S, Smith DA, Bancroft GJ. Cytokine and chemokine responses following pulmonary challenge with Aspergillus fumigatus: obligatory role of TNF-alpha and GM-CSF in neutrophil recruitment. Med Mycol. (1999) 37:183-94. doi: 10.1046/j.1365-280X.1999.00219.x

159. Roilides E, Dimitriadou-Georgiadou A, Sein T, Kadiltsoglou I, Walsh TJ. Tumor necrosis factor alpha enhances antifungal activities of polymorphonuclear and mononuclear phagocytes against Aspergillus fumigatus. Infect Immun. (1998) 66:5999-6003.

160. Brieland JK, Jackson C, Menzel F, Loebenberg D, Cacciapuoti A, Halpern $\mathrm{J}$, et al. Cytokine networking in lungs of immunocompetent mice in response to inhaled Aspergillus fumigatus. Infect Immun. (2001) 69:1554-60. doi: 10.1128/IAI.69.3.1554-1560.2001

161. Fleetwood AJ, Cook AD, Hamilton JA. Functions of granulocytemacrophage colony-stimulating factor. Crit Rev Immunol. (2005) 25:405-28. doi: 10.1615/CritRevImmunol.v25.i5.50

162. Kasahara S, Jhingran A, Dhingra S, Salem A, Cramer RA, Hohl TM. Role of granulocyte-macrophage colony-stimulating factor signaling in regulating neutrophil antifungal activity and the oxidative burst during respiratory fungal challenge. J Infect Dis. (2016) 213:1289-98. doi: 10.1093/infdis/jiw054

163. Retini C, Vecchiarelli A, Monari C, Tascini C, Bistoni F, Kozel TR. Capsular polysaccharide of Cryptococcus neoformans induces proinflammatory cytokine release by human neutrophils. Infect Immun. (1996) 64:2897-903.

164. Davis MJ, Tsang TM, Qiu Y, Dayrit JK, Freij JB, Huffnagle GB, et al. Macrophage M1/M2 polarization dynamically adapts to changes in cytokine microenvironments in Cryptococcus neoformans infection. MBio. (2013) 4:e00264-13. doi: 10.1128/mBio.00264-13
165. Shalit I, Halperin D, Haite D, Levitov A, Romano J, Osherov N, et al. Anti-inflammatory effects of moxifloxacin on IL-8, IL-1beta and TNF-alpha secretion and NFkappaB and MAP-kinase activation in human monocytes stimulated with Aspergillus fumigatus. J Antimicrob Chemother. (2006) 57:230-5. doi: 10.1093/jac/dki441

166. Moser C, Weiner DJ, Lysenko E, Bals R, Weiser JN, Wilson JM. betaDefensin 1 contributes to pulmonary innate immunity in mice. Infect Immun. (2002) 70:3068-72. doi: 10.1128/IAI.70.6.3068-3072.2002

167. Ordonez SR, Veldhuizen EJA, van Eijk M, Haagsman HP. Role of soluble innate effector molecules in pulmonary defense against fungal pathogens. Front Microbiol. (2017) 8:2098. doi: 10.3389/fmicb.2017.02098

168. Colley KJ, Beranek MC, Baenziger JU. Purification and characterization of the core-specific lectin from human serum and liver. Biochem J. (1988) 256:61-8. doi: 10.1042/bj2560061

169. Panepinto JC, Komperda KW, Hacham M, Shin S, Liu X, Williamson PR. Binding of serum mannan binding lectin to a cell integrity-defective Cryptococcus neoformans ccr4Delta mutant. Infect Immun. (2007) 75:476979. doi: 10.1128/IAI.00536-07

170. Kaur S, Gupta VK, Thiel S, Sarma PU, Madan T. Protective role of mannanbinding lectin in a murine model of invasive pulmonary aspergillosis. Clin Exp Immunol. (2007) 148:382-9. doi: 10.1111/j.1365-2249.2007.03351.x

171. Geunes-Boyer S, Oliver TN, Janbon G, Lodge JK, Heitman J, Perfect JR, et al. Surfactant protein D increases phagocytosis of hypocapsular Cryptococcus neoformans by murine macrophages and enhances fungal survival. Infect Immun. (2009) 77:2783-94. doi: 10.1128/IAI.00088-09

172. Geunes-Boyer S, Beers MF, Perfect JR, Heitman J, Wright JR. Surfactant protein D facilitates Cryptococcus neoformans infection. Infect Immun. (2012) 80:2444-53. doi: 10.1128/IAI.05613-11

173. Litvack ML, Palaniyar N. Review: soluble innate immune patternrecognition proteins for clearing dying cells and cellular components: implications on exacerbating or resolving inflammation. Innate Immun. (2010) 16:191-200. doi: 10.1177/1753425910369271

174. Bidula S, Sexton DW, Yates M, Abdolrasouli A, Shah A, Wallis R, et al. $\mathrm{H}$-ficolin binds Aspergillus fumigatus leading to activation of the lectin complement pathway and modulation of lung epithelial immune responses. Immunology. (2015) 146:281-91. doi: 10.1111/imm.12501

175. Bidula S, Sexton DW, Abdolrasouli A, Shah A, Reed A, ArmstrongJames D, et al. The serum opsonin L-ficolin is detected in lungs of human transplant recipients following fungal infections and modulates inflammation and killing of Aspergillus fumigatus. J Infect Dis. (2015) 212:234-46. doi: 10.1093/infdis/jiv027

176. Alekseeva L, Huet D, Femenia F, Mouyna I, Abdelouahab M, Cagna A, et al. Inducible expression of beta defensins by human respiratory epithelial cells exposed to Aspergillus fumigatus organisms. BMC Microbiol. (2009) 9:33. doi: 10.1186/1471-2180-9-33

177. Dubin RF, Robinson SK, Widdicombe JH. Secretion of lactoferrin and lysozyme by cultures of human airway epithelium. Am J Physiol Lung Cell Mol Physiol. (2004) 286:L750-5. doi: 10.1152/ajplung.00326.2003

178. Diamond RD, Krzesicki R, Epstein B, Jao W. Damage to hyphal forms of fungi by human leukocytes in vitro. A possible host defense mechanism in aspergillosis and mucormycosis. Am J Pathol. (1978) 91:313-28.

179. Cortopassi GA, Wilson AC. Recent origin of the P lysozyme gene in mice. Nucleic Acids Res. (1990) 18:1911. doi: 10.1093/nar/18.7.1911

180. Cross M, Mangelsdorf I, Wedel A, Renkawitz R. Mouse lysozyme M gene: isolation, characterization, and expression studies. Proc Natl Acad Sci USA. (1988) 85:6232-6. doi: 10.1073/pnas.85.17.6232

181. Steinbach WJ, Cramer RA Jr, Perfect BZ, Asfaw YG, Sauer TC, Najvar LK, et al. Calcineurin controls growth, morphology, and pathogenicity in Aspergillus fumigatus. Eukaryot Cell. (2006) 5:1091-103. doi: 10.1128/EC.00139-06

182. Cramer RA Jr, Perfect BZ, Pinchai N, Park S, Perlin DS, Asfaw YG, et al. Calcineurin target CrzA regulates conidial germination, hyphal growth, and pathogenesis of Aspergillus fumigatus. Eukaryot Cell. (2008) 7:1085-97. doi: 10.1128/EC.00086-08

183. da Silva Ferreira ME, Heinekamp T, Hartl A, Brakhage AA, Semighini CP, Harris SD, et al. Functional characterization of the 
Aspergillus fumigatus calcineurin. Fungal Genet Biol. (2007) 44:219-30. doi: 10.1016/j.fgb.2006.08.004

184. Steinbach WJ, Cramer RA Jr, Perfect BZ, Henn C, Nielsen K, Heitman J, et al. Calcineurin inhibition or mutation enhances cell wall inhibitors against Aspergillus fumigatus. Antimicrob Agents Chemother. (2007) 51:2979-81. doi: 10.1128/AAC.01394-06

185. Odom A, Muir S, Lim E, Toffaletti DL, Perfect J, Heitman J. Calcineurin is required for virulence of Cryptococcus neoformans. EMBO J. (1997) 16:257689. doi: $10.1093 / \mathrm{emboj} / 16.10 .2576$

186. Imbert S, Bresler P, Boissonnas A, Gauthier L, Souchet L, Uzunov M, et al. Calcineurin inhibitors impair neutrophil activity against Aspergillus fumigatus in allogeneic hematopoietic stem cell transplant recipients. $J$ Allergy Clin Immunol. (2016) 138:860-8. doi: 10.1016/j.jaci.2016.02.026

187. Herbst S, Shah A, Mazon Moya M, Marzola V, Jensen B, Reed A, et al. Phagocytosis-dependent activation of a TLR9-BTK-calcineurin-NFAT pathway co-ordinates innate immunity to Aspergillus fumigatus. EMBO Mol Med. (2015) 7:240-58. doi: 10.15252/emmm.201404556

188. Singh N, Alexander BD, Lortholary O, Dromer F, Gupta KL, John GT, et al. Cryptococcus neoformans in organ transplant recipients: impact of calcineurin-inhibitor agents on mortality. J Infect Dis. (2007) 195:756-64. doi: $10.1086 / 511438$

189. Levine B, Kroemer G. Autophagy in the pathogenesis of disease. Cell. (2008) 132:27-42. doi: 10.1016/j.cell.2007.12.018

190. Araya J, Hara H, Kuwano K. Autophagy in the pathogenesis of pulmonary disease. Intern Med. (2013) 52:2295-303. doi: 10.2169/internalmedicine.52.1118

191. Joven J, Guirro M, Marine-Casado R, Rodriguez-Gallego E, Menendez JA. Autophagy is an inflammation-related defensive mechanism against disease. Adv Exp Med Biol. (2014) 824:43-59. doi: 10.1007/978-3-319-07320-0_6

192. Racanelli AC, Kikkers SA, Choi AMK, Cloonan SM. Autophagy and inflammation in chronic respiratory disease. Autophagy. (2018) 14:221-32. doi: 10.1080/15548627.2017.1389823

193. Sharma V, Verma S, Seranova E, Sarkar S, Kumar D. Selective autophagy and xenophagy in infection and disease. Front Cell Dev Biol. (2018) 6:147. doi: 10.3389/fcell.2018.00147

194. Mao K, Klionsky DJ. Xenophagy: a battlefield between host and microbe, and a possible avenue for cancer treatment. Autophagy. (2017) 13:223-4. doi: 10.1080/15548627.2016.1267075

195. Romao S, Munz C. LC3-associated phagocytosis. Autophagy. (2014) 10:5268. doi: $10.4161 /$ auto. 27606

196. Lai SC, Devenish RJ. LC3-Associated Phagocytosis (LAP): connections with host autophagy. Cells. (2012) 1:396-408. doi: 10.3390/cells1030396

197. Cunha LD, Yang M, Carter R, Guy C, Harris L, Crawford JC, et al. LC3Associated phagocytosis in myeloid cells promotes tumor immune tolerance. Cell. (2018) 175:429-41 e16. doi: 10.1016/j.cell.2018.08.061
198. Nicola AM, Albuquerque P, Martinez LR, Dal-Rosso RA, Saylor C, De Jesus M, et al. Macrophage autophagy in immunity to Cryptococcus neoformans and Candida albicans. Infect Immun. (2012) 80:3065-76. doi: 10.1128/IAI.00358-12

199. Chamilos G, Akoumianaki T, Kyrmizi I, Brakhage A, Beauvais A, Latge JP. Melanin targets LC3-associated phagocytosis (LAP): a novel pathogenetic mechanism in fungal disease. Autophagy. (2016) 12:888-9. doi: 10.1080/15548627.2016.1157242

200. Akoumianaki T, Kyrmizi I, Valsecchi I, Gresnigt MS, Samonis G, Drakos E, et al. Aspergillus cell wall melanin blocks LC3-associated phagocytosis to promote pathogenicity. Cell Host Microbe. (2016) 19:79-90. doi: 10.1016/j.chom.2015.12.002

201. Sanjuan MA, Dillon CP, Tait SW, Moshiach S, Dorsey F, Connell S, et al. Toll-like receptor signalling in macrophages links the autophagy pathway to phagocytosis. Nature. (2007) 450:1253-7. doi: 10.1038/natu re06421

202. Martinez J, Almendinger J, Oberst A, Ness R, Dillon CP, Fitzgerald $\mathrm{P}$, et al. Microtubule-associated protein 1 light chain 3 alpha (LC3)associated phagocytosis is required for the efficient clearance of dead cells. Proc Natl Acad Sci USA. (2011) 108:17396-401. doi: 10.1073/pnas.11134 21108

203. Martinez J, Malireddi RK, Lu Q, Cunha LD, Pelletier S, Gingras S, et al. Molecular characterization of LC3-associated phagocytosis reveals distinct roles for Rubicon, NOX2 and autophagy proteins. Nat Cell Biol. (2015) 17:893-906. doi: 10.1038/ncb3192

204. Oliveira DL, Fonseca FL, Zamith-Miranda D, Nimrichter L, Rodrigues J, Pereira MD, et al. The putative autophagy regulator Atg7 affects the physiology and pathogenic mechanisms of Cryptococcus neoformans. Fut Microbiol. (2016) 11:1405-19. doi: 10.2217/fmb-20 16-0090

205. Hu G, Hacham M, Waterman SR, Panepinto J, Shin S, Liu X, et al. $\mathrm{PI} 3 \mathrm{~K}$ signaling of autophagy is required for starvation tolerance and virulence of Cryptococcus neoformans. J Clin Invest. (2008) 118:1186-97. doi: 10.1172/JCI32053

Conflict of Interest Statement: The authors declare that the research was conducted in the absence of any commercial or financial relationships that could be construed as a potential conflict of interest.

Copyright (c) $2019 \mathrm{Li}, \mathrm{Lu}$ and Meng. This is an open-access article distributed under the terms of the Creative Commons Attribution License (CC BY). The use, distribution or reproduction in other forums is permitted, provided the original author(s) and the copyright owner(s) are credited and that the original publication in this journal is cited, in accordance with accepted academic practice. No use, distribution or reproduction is permitted which does not comply with these terms. 